\title{
Identification of C. elegans DAF-12-binding sites, response elements, and target genes
}

\author{
Yuriy Shostak, ${ }^{1,2}$ Marc R. Van Gilst, ${ }^{2}$ Adam Antebi, ${ }^{3}$ and Keith R. Yamamoto ${ }^{1,2,4}$ \\ ${ }^{1}$ Program in Biochemistry and Molecular Biology and ${ }^{2}$ Department of Cellular and Molecular Pharmacology, University \\ of California, San Francisco, California 94143-2280, USA; ${ }^{3}$ Huffington Center on Aging, Baylor College of Medicine, \\ Houston, Texas 77030, USA
}

Intracellular receptor DAF-12 regulates dauer formation and developmental age and affects Caenorhabditis elegans lifespan. Genetic analyses place DAF-12 at the convergence of several signal transduction pathways; however, the downstream effectors and the molecular basis for the receptor's multiple physiological outputs are unknown. Beginning with C. elegans genomic DNA, we devised a procedure for multiple rounds of selection and amplification that yielded fragments bearing DAF-12-binding sites. These genomic fragments mediated DAF-12-dependent transcriptional regulation both in Saccharomyces cerevisiae and in C. elegans; that is, they served as functional DAF-12 response elements. We determined that most of the genomic fragments that displayed DAF-12 response element activity in yeast were linked to genes that were regulated by DAF-12 in C. elegans; indeed, the response element-containing fragments typically resided within clusters of DAF-12-regulated genes. DAF-12 target gene regulation was developmental program and stage specific, potentially predicting a fit of these targets into regulatory networks governing aspects of C. elegans reproductive development and dauer formation.

[Keywords: DAF-12; In Vitro Genomic Selection; intracellular receptor; response element; target genes]

Supplemental material is available at http://www.genesdev.org.

Received May 6, 2004; revised version accepted August 23, 2004.

Intracellular receptors (IRs) are transcriptional regulatory factors that bind to hormone response elements and modulate transcription of target genes. IRs control global developmental and physiological gene networks; a given IR typically plays distinct roles in different tissues and developmental times (Ashburner 1990; Yamamoto et al. 1992; Tsai and O'Malley 1994; Yamamoto 1995; Chawla et al. 2001; Thummel 2001). For example, mammalian glucocorticoid receptor, in response to glucocorticoids, activates or represses transcription to regulate developmental and homeostatic processes from birth through adulthood, such as metabolic effects in liver, lung development, heart and brain function, and immune regulation. Understanding how these gene networks are organized and function will have important implications, but such analyses are very difficult in mammals. Caenorhabditis elegans, with its sequenced genome, fully determined cell lineage, facile genetics, and well-studied developmental processes, provides a powerful alternative for the investigation of gene networks; in particular,

\footnotetext{
${ }^{4}$ Corresponding author.

E-MAIL yamamoto@cgl.ucsf.edu; FAX (415) 476-6129.

Article and publication are at http://www.genesdev.org/cgi/doi/10.1101/ gad.1218504
}

IRs comprise a family of 284 members (commonly denoted in C. elegans as nuclear hormone receptors) (Sluder and Maina 2001).

The nematode C. elegans develops in $2 \mathrm{~d}$ from embryos, through four larval stages L1-L4, to adults. During the 2-3-wk C. elegans life cycle, IR DAF-12 (Antebi et al. 2000; Snow and Larsen 2000) functions as a developmental regulator with at least three broad phenotypic effects. First, in response to unfavorable environmental conditions, including lack of food, overcrowding, and elevated temperature, DAF-12 drives formation of dauer larvae (Riddle et al. 1981). Dauers are long-lived, nonfeeding, stress-resistant specialized L3 larvae that resume development on return to favorable conditions (Riddle and Albert 1997). Second, DAF-12 functions as a heterochronic gene to regulate $C$. elegans developmental age (Antebi et al. 1998). Finally, DAF-12 affects C. elegans adult lifespan (Larsen et al. 1995; Gems et al. 1998; Hsin and Kenyon 1999; Gerisch et al. 2001; Jia et al. 2002).

Multiple alleles of daf-12 with distinct protein sequence alterations partially uncouple its phenotypic effects (Antebi et al. 2000). Genetic analyses place DAF-12, as dauer regulator, at the convergence of TGF- $\beta$ (transforming growth factor $\beta$ ), cGMP (cycle guanosine $3^{\prime}-5^{\prime}$ monophosphate), and insulin/IGF-I (insulin growth fac- 
Shostak et al.

tor I)-like signaling pathways (Riddle and Albert 1997). This implies that DAF-12 and other C. elegans receptors, like mammalian IRs, control broad and diverse gene networks (Sengupta et al. 1994; Larsen et al. 1995; Antebi et al. 1998; Carmi et al. 1998; Kostrouchova et al. 1998; Hsin and Kenyon 1999; Asahina et al. 2000; Gissendanner and Sluder 2000; Much et al. 2000; Lindblom et al. 2001). However, as in mammals, the downstream effectors and the mechanistic basis for the multiple outputs of DAF-12 are unknown. Moreover, unlike mammals, little is known about the molecular biology and molecular physiology of C. elegans IR action, that is, ligands, genomic binding sites, response elements, or target genes have not been identified. Thus, to exploit the advantages of $C$. elegans toward deciphering DAF-12 gene networks, we must first investigate the molecular biology of DAF-12 action.

As one approach, random selection and amplification methodologies (Blackwell and Weintraub 1990) might be used to identify high-affinity binding sites for DAF-12.
However, such sequences would not necessarily represent bona fide response elements, nor would they identify genes regulated by DAF-12. In this study, we sought to develop an approach in which, starting with the $C$. elegans genome, we could search biochemically for genomic fragments bound by DAF-12, identify binding sites, test their activities as response elements, and identify DAF-12 target genes.

\section{Results}

\section{In Vitro Genomic Selection}

Drawing from concepts of exponential enrichment methodology (Blackwell and Weintraub 1990; Ellington and Szostak 1990; Tuerk and Gold 1990; Shtatland et al. 2000), we developed an in vitro selection and amplification method, In Vitro Genomic Selection, in which immobilized recombinant DAF-12 DNA-binding domain (DAF-12 DBD) was used to screen total C. elegans genomic DNA digested with restriction endonuclease
A

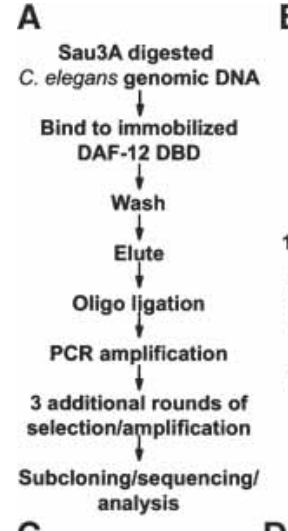

C

$2^{\text {nd }}$ PCR

Template $(\mu \mathrm{L})$

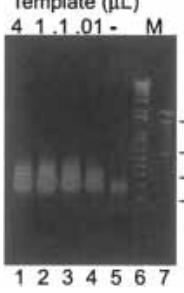

D
B
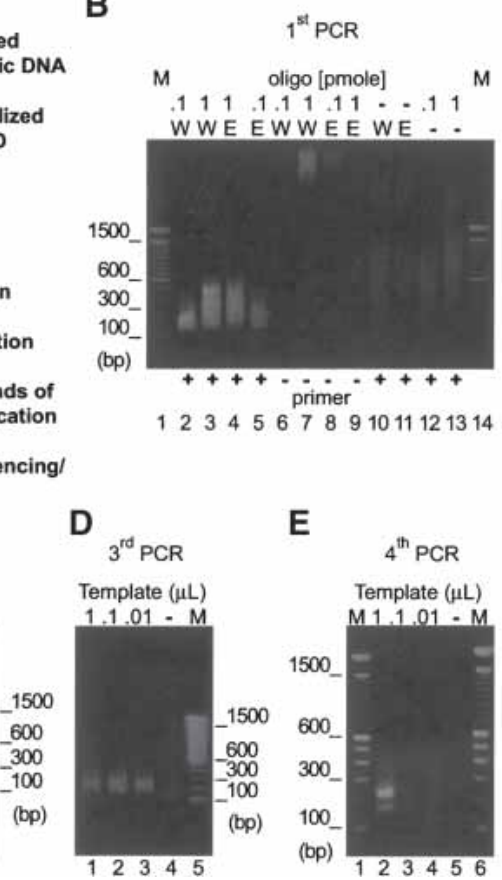

F

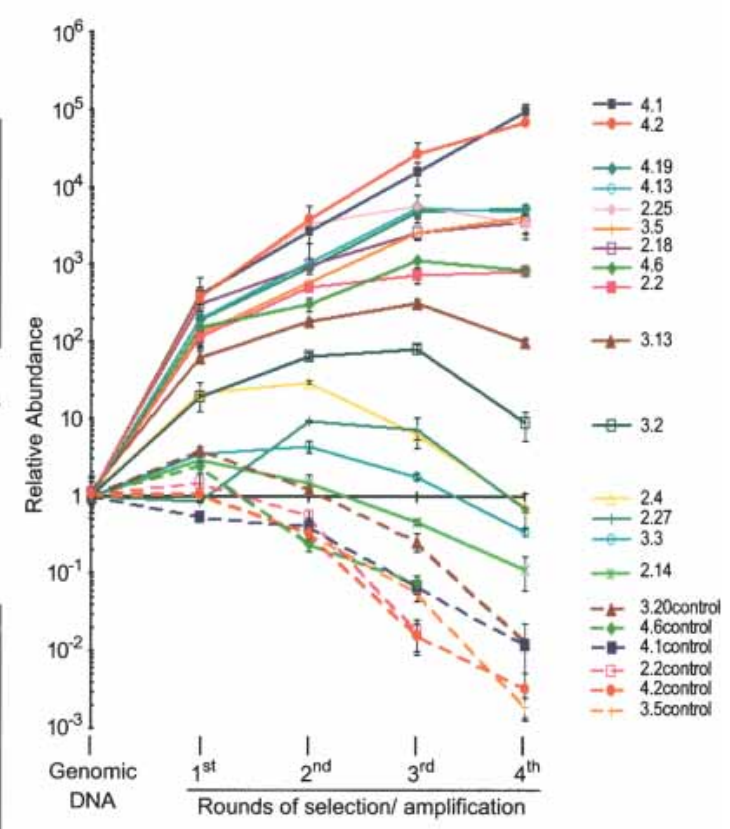

Figure 1. In Vitro Genomic Selection of C. elegans DNA fragments containing DAF-12-binding sites. $(A)$ Flow chart of the method. $(B-E)$ PCR amplification of the genomic fragments after each selection round. (M) DNA ladder. (B) First PCR. Prior to the first PCR, NotISau3A oligonucleotides (1 or 0.1 pmole) were ligated to either elution (E; lanes $4,5,8,9)$ or $0.5 \mathrm{M}$ salt wash (W; lanes 2,3,6,7) fractions from the first selection round. The DNA mixture amplified with 0.1 pmole of the oligo ligated to the elution fraction (lane 5) was used for a subsequent selection round. (Lanes 6-9) PCR reactions without primer added. In lanes 10 and 11, PCR was performed with the wash (W) or elution (E) fraction without NotISau3A oligonucleotides ligated. (Lanes 12,13) PCR with only NotISau3A oligonucleotides as templates. (Lanes 6-13) Control PCR reactions. (C) Second PCR. DNA amplified from 1- $\mu \mathrm{L}$ template (lane 2) was used for the next round of selection. $(D)$ Third PCR. As in $C$, amplified mixture from $0.1 \mu \mathrm{L}$ template (lane 2) was used for the fourth selection round. $(E)$ Fourth PCR. Similar to $C$ and $D$, mixture amplified with $1-\mu L$ template (lane 2) was used for the subcloning step. $($ Lanes 2,3) The appearance of discrete bands suggests preferential amplification of particular genomic fragments. $(F)$ Specific enrichment of C. elegans genomic fragments isolated by In Vitro Genomic Selection. qRT PCR analysis of C. elegans genomic fragments identified by In Vitro Genomic Selection, together with nonspecific control fragments from fragment mixtures after each of four rounds of selection and amplification. For each genomic fragment's primer pairs, values were normalized to the amplification levels of Sau3A-digested total C. elegans genomic DNA; for each fragment, relative abundance within genomic DNA was assigned a value of one. Control fragments were chosen from sequences $<2 \mathrm{~kb}$ from the corresponding specific genomic selection fragments. 
Sau3AI. The fragments that emerge contain DNA sequences bound directly by DAF-12, and in contrast to synthetic optimized sequences, the binding sites reside in their native C. elegans genomic context. This method is distinct from those in which the bound fragments are incorporated into libraries (Sompayrac and Danna 1990) or those that use indirect readouts of DNA:protein interactions (Wilson et al. 1991). Kinzler and Vogelstein (1989) described Whole Genome PCR to identify genomic fragments containing previously known transcription factor-binding sites. We used In Vitro Genomic Selection to identify unknown DAF-12-binding sites, response elements, and DAF-12-regulated target genes.

After four rounds of selection and PCR amplification (Fig. 1A-E), we isolated 47 clones containing C. elegans genomic DNA fragments that selectively bound to DAF12; these clones represented 26 distinct genomic fragments (Table 1; Supplementary Table S1). Ten of the 26 fragments were overrepresented; three fragments denoted 4.1, 4.2, and 4.3 were recovered five, seven, and six times, respectively; one fragment was recovered three times, and six fragments were recovered twice (Supplementary Table S1).

Sequence inspection (Supplementary Fig. S1) revealed that fragments $4.1,4.2$, and 4.3 each contained multiple hexamers closely related to AGTTCA and AGTGCA, which are similar to the consensus "binding half-sites" for the mammalian vitamin D receptor (Freedman et al. 1994) and Drosophila melanogaster DHR96 (Fisk and Thummel 1995), respectively, IRs whose DBDs are most similar to that of DAF-12. Moreover, some of the hexamers on 4.1 and 4.2 were arranged as direct repeats separated by 5 bp (DR5 elements). IR DNA-binding sites commonly consist of two variously spaced hexamers arranged as direct or inverted repeats, or a single hexamer (Rastinejad 1998). Interestingly, 22 of the 26 unique $C$. elegans genomic fragments also contained AGTTCA-related hexamers, and 12 contained DR5 elements (Table 2). Thus, the common hexamers and DR5 elements in the isolated C. elegans genomic fragments might correspond to DAF-12-binding sites.

In addition to analyzing recovered fragments after four rounds of selection and amplification, we cloned and analyzed recovered fragments after three and two rounds of In Vitro Genomic Selection. We found that 46 clones containing $C$. elegans genomic fragments after three rounds of selection included 19 fragments (eight of them distinct) that were also recovered in the fourth round of selection (Supplementary Tables S1, S2; Table 1). In contrast, 42 clones containing C. elegans genomic fragments after two rounds of selection included four fragments (three distinct) recovered in the fourth round (Supplementary Table S1) and one fragment recovered in the third round (Supplementary Tables S2, S3; Table 1). Thus, certain C. elegans fragments were selectively enriched after four rounds of selection, as measured by their recovery in successive rounds and by recovery of particular fragments multiple times within a single round.

We compared by quantitative real-time (qRT) PCR the relative abundance of 15 recovered genomic fragments (from the fourth, third, and second rounds of selection, normalized to total genomic DNA) and six neighboring nonspecific control genomic fragments, revealing up to $10^{5}$-fold enrichment of specific fragments, such as 4.1 and 4.2 , and up to $10^{3}$-fold loss of neighboring nonspecific fragments, including 4.1 control and 4.2control (Fig. $1 F)$. The 4.1 and 4.2 fragments were enriched more than $10^{7}$-fold over the corresponding nonspecific control fragments. During successive rounds of selection and amplification, six of 10 qRT PCR-analyzed fragments recovered in the third and second rounds of the selection showed decreased enrichment after the second or third round; after the fourth round, the abundance levels of 4 fragments, 2.4, 2.14, 2.27, and 3.3, fell below the starting levels (setting as 1 the starting abundance of each fragment of total C. elegans genomic DNA), suggesting that those fragments are likely nonspecific. In contrast, each of the five examined fragments from the fourth round $(4.1,4.2,4.6,4.13$, and 4.19) was enriched throughout the procedure (Fig. 1F). We conclude that during In Vitro Genomic Selection, particular C. elegans fragments, likely those with the highest relative affinity for DAF12 , were progressively enriched with successive rounds of selection and amplification, whereas nonspecific genomic fragments were lost.

Table 1. Summary of the DAF-12 In Vitro Genomic Selection

\begin{tabular}{|c|c|c|c|c|c|c|c|}
\hline $\begin{array}{l}\text { Genomic } \\
\text { selection } \\
\text { round }\end{array}$ & $\begin{array}{l}\text { Total } \\
\text { genomic } \\
\text { fragments } \\
\text { isolated }^{\mathrm{a}}\end{array}$ & $\begin{array}{l}\text { Unique } \\
\text { genomic } \\
\text { fragments } \\
\text { isolated }^{\mathrm{a}}\end{array}$ & $\begin{array}{l}\text { Unique } \\
\text { fragments } \\
\text { active in } \\
\text { yeast }^{\mathrm{a}, \mathrm{b}}\end{array}$ & $\begin{array}{c}\text { Fraction of } \\
\text { active } \\
\text { fragments }^{\mathrm{a}, \mathrm{b}}\end{array}$ & $\begin{array}{c}\text { Active } \\
\text { fragments } \\
\text { linked } \\
\text { to target } \\
\text { genes }^{\mathrm{a}, \mathrm{b}, \mathrm{c}}\end{array}$ & $\begin{array}{l}\text { Target } \\
\text { genes }^{c}\end{array}$ & $\begin{array}{c}\text { Target } \\
\text { gene } \\
\text { clusters }\end{array}$ \\
\hline $2^{\text {nd }}$ & 42 & 37 & 7 & $19 \%$ & $\geq 4$ & $\geq 14$ & $\geq 4$ \\
\hline $3^{\mathrm{rd}}$ & 46 & 27 & 9 & $33 \%$ & $\geq 7$ & $\geq 11$ & $\geq 3$ \\
\hline $4^{\text {th }}$ & 47 & 26 & 14 & $54 \%$ & $\geq 10$ & $\geq 15$ & $\geq 3$ \\
\hline Total & 135 & 90 & 30 & $33 \%$ & $\geq 21$ & $\geq 40$ & $\geq 10$ \\
\hline
\end{tabular}

${ }^{\mathrm{a} C}$ C. elegans genomic fragments.

${ }^{\mathrm{b} D A F-12}$ N500-dependent transcriptional activation in yeast.

${ }^{\mathrm{c}}$ DAF-12-dependent regulation of target genes in C. elegans.

${ }^{\mathrm{d}}$ Two or more DAF-12-regulated target genes nearby a particular active genomic fragment. 
Table 2. Common hexamers and DR5 elements in the C. elegans genomic fragments isolated by In Vitro Genomic Selection after four rounds of selection and amplification

\begin{tabular}{|c|c|c|}
\hline $\begin{array}{l}\text { Genomic } \\
\text { selection } \\
\text { clone \# }\end{array}$ & $\begin{array}{l}\text { AGTGCA-related } \\
\text { hexamers present }^{\mathrm{a}}\end{array}$ & $\begin{array}{l}\text { Txn. activ. } \\
\text { (fold })^{\mathrm{b}}\end{array}$ \\
\hline 4.1 & $\begin{array}{l}\text { AGTTCAgaaatAGGACA, AGTGCA, } \\
\text { AGTACA }\end{array}$ & 41 \\
\hline 4.2 & $\begin{array}{l}\text { AGGACAcaaaaAGTGCA, AGTGCG, } \\
\text { 3xAGGACA }\end{array}$ & 182 \\
\hline 4.3 & 8x AGTGCA & 20 \\
\hline 4.4 & AGTTCAagttgAGTACA & 9 \\
\hline 4.5 & AGTGCT & - \\
\hline 4.6 & AGTTCAtataaAGTGCA & 16 \\
\hline 4.7 & AGTGCA (IR2) & 17 \\
\hline 4.8 & AGTGCG & - \\
\hline 4.09 & AGTGCA & - \\
\hline 4.10 & AGTGCAacaagAGGACA & 5 \\
\hline 4.11 & AGTGCA (IR-4) & - \\
\hline 4.12 & AGTGCAgaaagAGTGCC & - \\
\hline 4.13 & AGTGCAattaaAGTTCA & 3 \\
\hline 4.14 & $\begin{array}{l}\text { AGTTCAtacagAGTTCA, AGTTCA, } \\
\text { 3x AGTGCG }\end{array}$ & 24 \\
\hline 4.15 & AGTTCAtacaaAGTAAC, AGTACA & 53 \\
\hline 4.16 & AGTACA & - \\
\hline 4.17 & none? (AGGTCA) & - \\
\hline 4.18 & none? (AGGTCA) & - \\
\hline 4.19 & AGTACTaaaaAGTGCA & 152 \\
\hline 4.20 & none? & - \\
\hline 4.21 & AGTTCAatgtgAGTACA & 4 \\
\hline 4.22 & AGTGCA & 10 \\
\hline 4.23 & $\begin{array}{l}\text { CGTTCA, AGTGGG, } \\
\text { AGTGGGgagagAGTGGA }\end{array}$ & - \\
\hline 4.24 & (AGGTCA)ttttgAGTACA & 16 \\
\hline 4.25 & none? & - \\
\hline
\end{tabular}

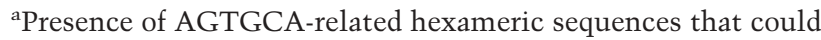
serve as putative DAF-12 binding sites and response elements. ${ }^{b}$ DAF-12 N500 and C. elegans genomic fragment-dependent transcriptional activation in yeast.

Selected C. elegans genomic fragments display DAF-12 response element activity in yeast

We carried out a functional assay in Saccharomyces cerevisiae to determine if the three most overrepresented C. elegans DNA fragments isolated by In Vitro Genomic Selection conferred DAF-12 response element activity. Although yeast lacks IRs and metazoan-specific cofactors, it has proved useful as a simplified physiological setting for studies of mammalian IR activities (Schena and Yamamoto 1988). Curiously, response elements that confer negative or positive regulation in a given mammalian context typically display positive regulatory activity in yeast; thus, yeast identifies many functional response elements but does not reliably indicate the direction of regulation.

We found that full-length DAF-12 weakly activated transcription from yeast promoter-reporter constructs bearing linked 4.1 or 4.2 sequences and failed to activate from the 4.3 sequence (Fig. 2A-C). Such weak activity in yeast might be expected if DAF-12 action in C. elegans is normally dependent on binding a hormonal ligand. Indeed, mammalian glucocorticoid and androgen receptors are nearly inactive in the absence of their cognate ligands; however, derivatives of these receptors lacking their C-terminal ligand-binding domains (LBDs) behave as constitutive activators (Godowski et al. 1987; Rundlett et al. 1990). Correspondingly, we found that a truncated DAF-12 lacking its putative LBD, DAF-12 N500, activated transcription robustly from all three reporter constructs (Fig. 2D-F); as a control, the DAF-12 DBD alone was inactive. Thus, these experiments show that $4.1,4.2$, and 4.3 fragments can serve as DAF-12 response elements in yeast and suggest that DAF-12 function may be ligand dependent.

In view of these results, we tested the DAF-12-dependent response element activity in yeast of all fragments recovered after the fourth, third, and second rounds of In Vitro Genomic Selection. We found that $19 \%$ of the unique fragments (seven of 37) isolated in the second round were active (Table 1; Supplementary Table S3; Fig. $2 \mathrm{I}), 33 \%$ recovered in the third round were active (Table 1; Supplementary Table S2; Fig. $2 \mathrm{H}$ ), and $54 \%$ of fragments from the fourth round had DAF-12-dependent response element activity (Tables 1, 2; Supplementary Table S1; Fig. 2G). Notably, certain fragments recovered in early rounds but not retained in the fourth round, 2.4, 2.14, 2.27, and 3.3 (Fig. 1F), failed to display DAF-12dependent response element activity in yeast (Fig. 2H,I), whereas many of the most enriched fragments (Fig. 1F) were active (Fig. 2G-I).

\section{DR5 elements function as DAF-12-binding sites and response elements}

We next conducted in vitro binding experiments using fluorescence anisotropy with labeled oligonucleotides. DAF-12 bound with high affinity to an oligonucleotide bearing the DR5 sequence from 4.2 genomic fragment (DR5gt, Fig. 3A). As DR5gt contained two distinct hexamers (AGGACA and AGTGCA), we investigated their relative affinities. A synthetic DR5 element bearing two AGTGCA hexamers (DR5tt) bound to DAF-12 with a higher affinity than the natural DR5gt element (Fig. 3A), suggesting that AGTGCA might serve as a high-affinity binding half-site for DAF-12.

We conducted in vitro binding competition experiments to address the specificity and relative affinities of DAF-12 binding to various DR5 elements in the isolated genomic fragments (Fig. 3B). Mutations in either or both of the hexamers in the DR5 elements $(\mathrm{m} 2, \mathrm{~m} 3$, and $\mathrm{m} 4$, Fig. 3C) yielded fragments that were compromised, relative to wild type, in their competition with DR5gt (Fig. 3B); as expected, mutations in the AGTGCA half-site were more deleterious than those in the AGGACA halfsite. In contrast, DR5gt derivatives bearing the AGGACA half-site, together with a hexamer from either 4.2 or4.1 (AGTGCG and AGTTCA-m5 and m6, respectively), competed well with DR5gt, albeit less efficiently than wild type. We conclude that DAF-12 binds specifically to 
A

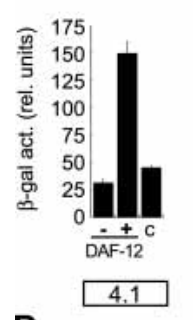

D

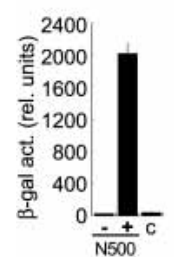

B
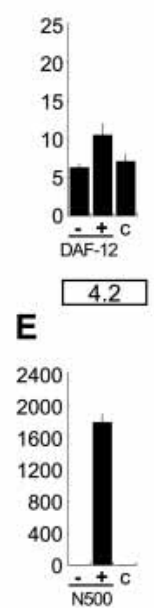

C
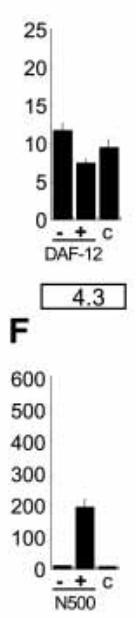

G $\quad 4^{\text {th }}$ round fragments:

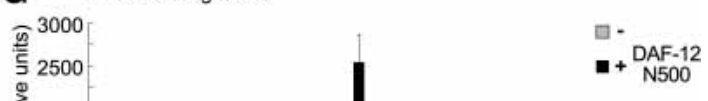

I $\quad 2^{\text {nd }}$ round fragments:

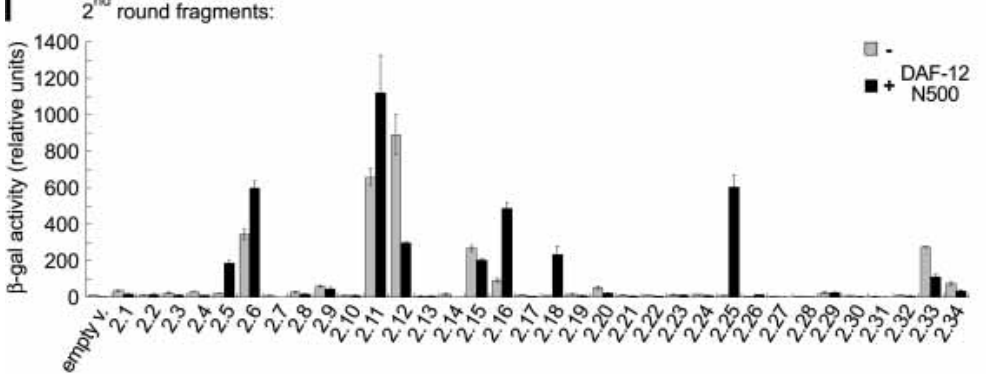

Figure 2. Selected C. elegans genomic fragments display DAF-12 response element activity in yeast. Full-length DAF-12 displays little activity $(A-C)$, whereas robust transcriptional activation is conferred by the putative LBD-truncated DAF-12 N500 (D-F) in yeast from $4.1(A, D), 4.2(B, E)$, and 4.3 fragments $(C, F)$. DAF-12 DBD was used as a control $(\mathrm{c})$ in $A-F$. Minus sign $(-)$ or plus sign $(+)$ indicates absence or presence of DAF-12, respectively. DAF-12-dependent transcriptional activation in yeast was assessed for each C. elegans genomic fragment isolated after the fourth $(G)$, third $(H)$, and second $(I)$ rounds of In Vitro Genomic Selection. In $G-I$, gray bars represent the transcriptional activity of the genomic fragments in the absence of DAF-12 (basal); black bars represent the activity in the presence of DAF-12 N500 (activated transcription).

the DR5gt sequence and that the related hexameric sequences were DAF-12-binding half-sites with lower affinity than AGTGCA.

We next determined whether the DR5-bearing oligonucleotides were sufficient to mediate DAF-12 N500dependent activation in yeast. As shown in Figure 3D, a single DR5gt sequence was indeed competent to mediate a DAF-12 response. Furthermore, mutant elements with decreased DAF-12 binding affinity (Fig. 3B) conferred little or no transcriptional activity (Fig. 3D), whereas mutations outside the DAF-12 recognition sequences (DR5 m0) did not affect activity. Finally, 5-bp spacing between half-sites in a direct repeat orientation displayed strong response element activity, and increased spacing (to seven bases, DR5 + sp2, Fig. 3C), decreased spacing (DR0-4, Fig. 3C), or an inverted repeat configuration with various spacing (IR0-5, 7, Fig. 3C) reduced or eliminated the activity (Fig. 3D,E). Interestingly, DAF-12 N500 activated at moderate levels from DR4, DR3, and IR2 elements (Fig. 3E). Indeed, one of the recovered fragments, 4.7, which was active in yeast (Fig. 2G), con- tained an IR2 element (Table 2). Thus, DR5 is sufficient and an element containing two half-sites appears to be necessary for DAF-12 response element activity in yeast.

We found that two other C. elegans IRs, CHR3 (Kostrouchova et al. 1998) and NHR-25 (Gissendanner and Sluder 2000), failed to activate transcription from the DR5gt DAF-12 response element, whereas DAF-12 was inactive at response elements (identified by $M$. Van Gilst, unpubl.) specific to CHR3 or NHR-25; DAF-12 also failed to activate transcription from a vertebrate IR response element-containing consensus AGGTCA halfsites (data not shown). Furthermore, transcriptional activation from the 4.2 fragment required functional DAF12, as a DAF-12 DBD mutant (Antebi et al. 2000) that is inactive in C. elegans was similarly devoid of activity in the yeast reporter assay (data not shown). Thus, although further study will likely reveal context effects that complicate this picture (Yamamoto et al. 1998), it is apparent that DAF-12 action is selective and response element specific. 
Shostak et al.

A

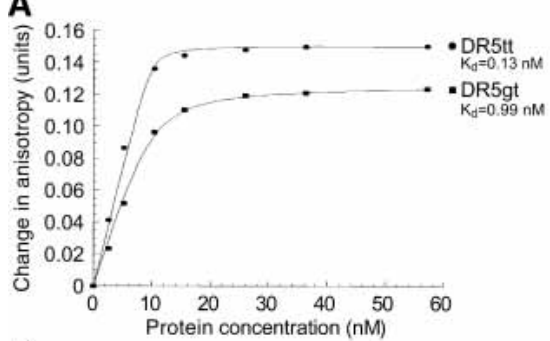

C

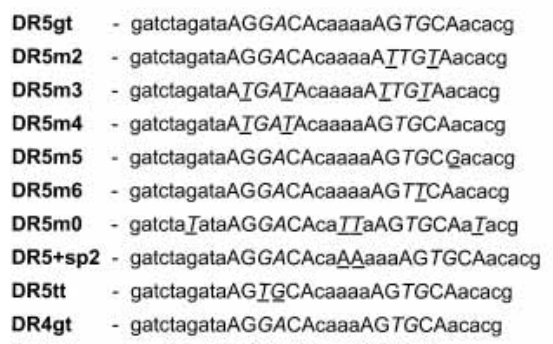

DR4gt - gatctagataAGGACAcaaaAGTGCAacacg

DR3gt - gatctagataAGGACAcaaAGTGCAacacg

DR2gt - gatctagataAGGACAcaAGTGCAacacg

DR1gt - gatctagataAGGACAaAGTGCAacacg

DR0gt - gatctagataAGGACAAGTGCAacacg

IR0gt - gatctagataAGGACATGCACTacacg

IR1gt - gatctagataAGGACAaTGCACTacacg

IR2gt - gatctagataAGGACAcaTGCACTacacg

IR3gt - gatctagataAGGACAcaaTGCACTacacg

IR4gt - gatctagataAGGACAcaaaTGCACTacacg

IR5gt - gatctagataAGGACAcaaaaTGCACTacacg

IR7gt - gatctagataAGGACAcaaaaaTGCACTacacg
B

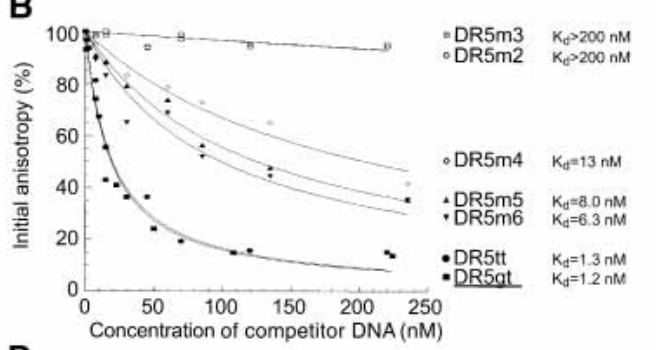

D
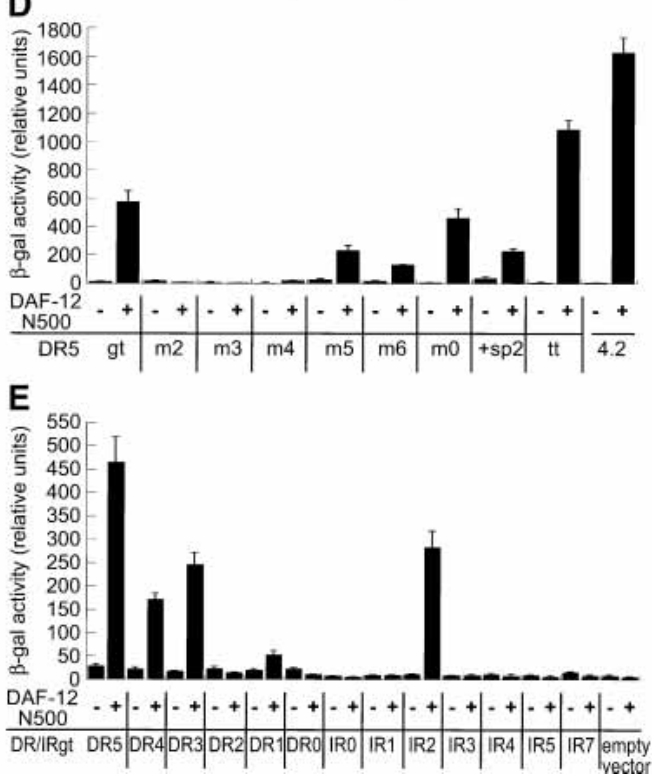

Figure 3. DR5 elements function as DAF-12-binding sites and response elements. (A) Binding of GST-DAF-12 DBD to fluoresceinlabeled double-stranded oligonucleotides carrying the DR5gt element (10 nM) from 4.2 or its derivative, DR5tt, was measured by fluorescence anisotropy. Protein concentrations shown assume GST-DAF-12 DBD homodimer. Apparent $\mathrm{K}_{\mathrm{d}} \mathrm{s}$ were calculated from curve fits. (B) Binding of $15 \mathrm{nM}$ of GST-DAF12 DBD to $1 \mathrm{nM}$ of DR5gt was competed in vitro with various mutated DR5s and

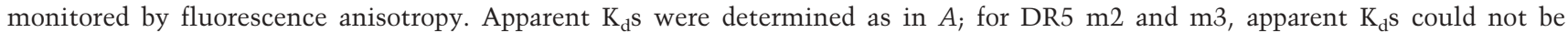
determined precisely. $(C)$ Sequences of wild-type and mutated DR5 elements used in in vitro binding and competition experiments $(A, B)$; regulatory activity assays $(D)$; and DR5-derived direct and inverted repeats with various separating spacing used in regulatory activity assays $(E)$. $(D)$ Regulatory activity of DAF-12 N500 from wild-type and mutated DR5s in yeast. $(E)$ Regulatory activity in yeast of DAF-12 N500 from direct and inverted repeats with various spacing.

Multiple DAF-12-binding half-sites contribute to overall response element activity from the selected C. elegans genomic fragments

We found that mutations of "solo" half-sites (those not in the DR5 configuration; Supplementary Fig. S2A) within 4.2 modestly reduced DAF-12-mediated activation in yeast and that combinations of mutated half-sites greatly decreased or abolished activity (Supplementary Fig. S2B-D). Double and triple mutations within AGGACA half-sites $(\mathrm{m} 01, \mathrm{~m} 41, \mathrm{~m} 51$; Supplementary Fig. S2D) had less pronounced effects than did double mutants within the AGTGCA and AGTGCG elements (m1, m21, m31), consistent with our in vitro binding competition assay results. Similar results were obtained with the 4.1 fragment, where mutations in a solo halfsite (m21) or in a DR5 element (m11) decreased slightly the activation by DAF-12 but in combination abolished activation (Supplementary Fig. S2E-F). We conclude that the 4.2 and 4.1 genomic fragments carry composite re- sponse elements, each bearing multiple functional hexameric DAF-12-binding sites; it is likely that In Vitro Genomic Selection biases toward recovery of DNA fragments carrying multiple binding sites for the selecting protein. Such complex organization seems to be characteristic of many normal genomic enhancers (Payvar et al. 1982; Huang et al. 1999).

\section{DAF-12 regulates LIT-1 gene expression in C. elegans}

We next tested whether DAF-12 could activate transcription in C. elegans from a green fluorescent protein (GFP) reporter gene linked to 4.2. As seen in Figure 4A, the microinjected reporter was strongly expressed in the larval and adult pharynx of wild-type N2 C. elegans, whereas expression was dramatically reduced in an isogenic strain (rh61rh412) carrying a loss-of-function daf12 null-like allele (Antebi et al. 2000) (Fig. 4C). Furthermore, injection of a reporter bearing the $4.2 \mathrm{~m} 11 \mathrm{~m} 31$ 

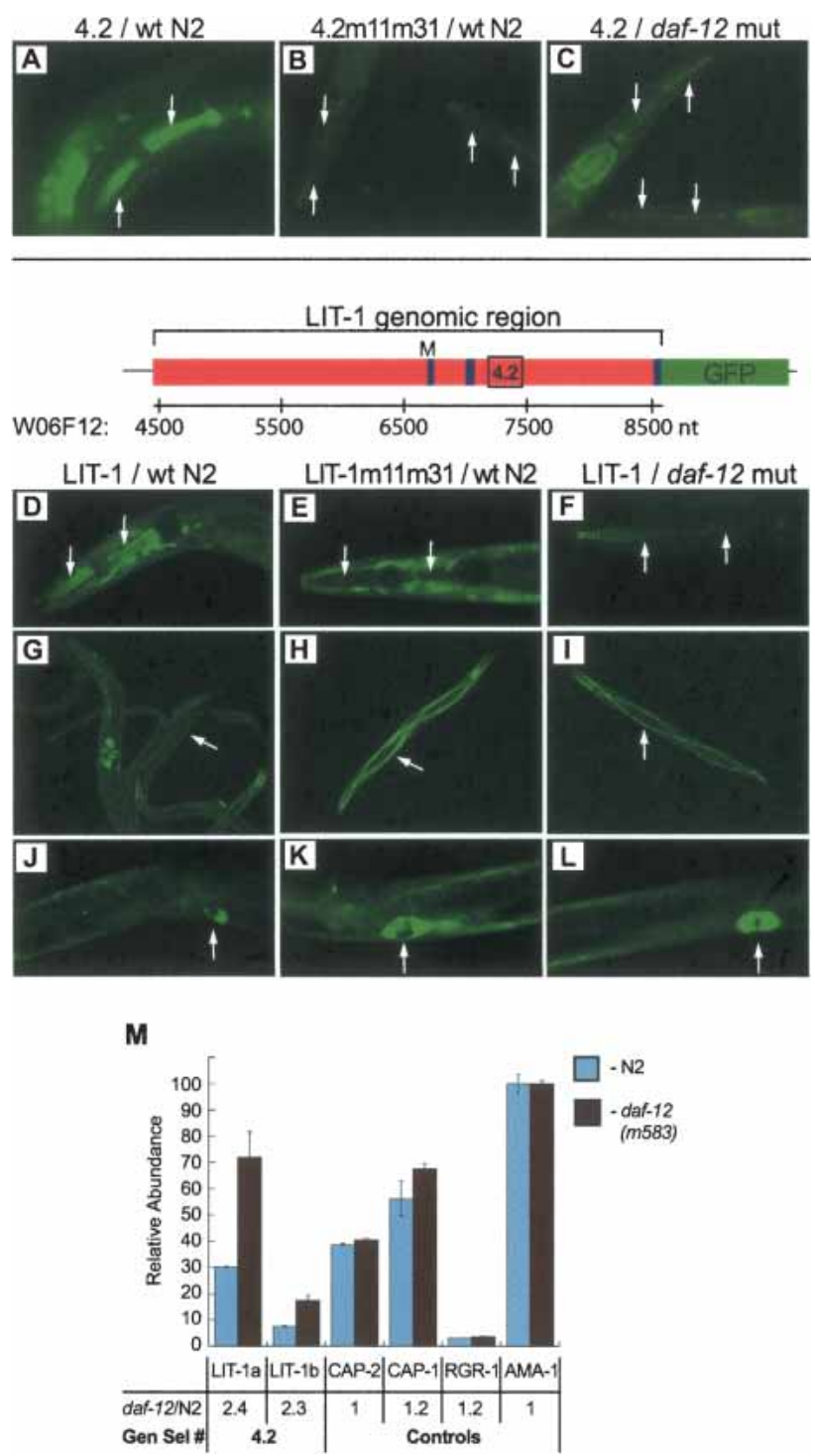

mutant element into N2 C. elegans yielded little GFP expression (Fig. 4B). Thus, a genomic DNA fragment bound specifically by DAF-12 in vitro displayed DAF-12 response element activity in vivo both in yeast and in $C$. elegans. Moreover, DAF-12-activated transcription from the 4.2 sequences in $C$. elegans was tissue specific.

Within the C. elegans genome, the 4.2 fragment resides in an intron of the LIT-1 kinase gene. To assess whether DAF-12 regulates LIT-1 gene expression via 4.2 in C. elegans, we constructed and microinjected LIT-1GFP in-frame fusion constructs, containing $2 \mathrm{~kb}$ of upstream DNA and the first $2 \mathrm{~kb}$ of the LIT-1 transcription unit (LIT-1b isoform). LIT-1-GFP expression was observed in various tissues and developmental stages in N2 animals, notably in larval and adult pharynx (Fig. 4D); pharyngeal LIT-1 expression has been previously observed (Gaudet and Mango 2002). Pharyngeal expression was abrogated in constructs bearing the $4.2 \mathrm{~m} 11 \mathrm{~m} 31$ mutations (Fig. 4E). Correspondingly, wild-type LIT-1-
Figure 4. DAF-12 regulates LIT-1 gene expression in C. elegans. In $A-C$, the wild-type or $\mathrm{m} 11 \mathrm{~m} 31$ mutant 4.2 fragment was subcloned upstream of a minimal pes-10 promoter driving GFP expression and microinjected into wild-type or daf-12 mutant rh61rh412 C. elegans. (A) GFP expression in the pharynx (arrows) in N2 worms with wild-type 4.2. (B) Absence of GFP pharyngeal expression in $\mathrm{N} 2$ worms injected with the $4.2 \mathrm{~m} 11 \mathrm{~m} 31$ mutant reporter. One-hundred percent of animals exhibited the effect. (C) Reduced GFP expression in daf-12 mutant worms (arrows) injected with wild-type 4.2 fragment. In four independent injections, $>90 \%$ of animals exhibited the effect in three cases; in the fourth, $50 \%$ displayed the reduction. $(D-L)$ A 4-kb LIT-1 genomic segment (nucleotides 4527-8561 from cosmid W06F12, with upstream/intronic sequences in red and exons in blue) with the LIT-1b initiating methionine codon (M) at its midpoint, and bearing either the wild-type or $\mathrm{m} 11 \mathrm{~m} 31$ 4.2 segment in its second intron (nucleotides 7201-7408), was fused in frame to GFP and microinjected into wild-type or daf12 mutant rh61rh412 C. elegans. $(D-F)$ LIT-1-GFP expression in pharynx (arrows) with wild-type or $\mathrm{m} 11 \mathrm{~m} 314.2$ constructs in L4 N2 worms, or with wild-type 4.2 constructs in daf-12 mutant worms, respectively. In $E, 100 \%$ of animals had no pharyngeal GFP expression; in $F$, $>90 \%$ of animals had reduced GFP expression in pharynx. $(G)$ Low levels of LIT-1-GFP expression from 4.2 construct in seam cells of L4 N2 animals (arrow); GFP expression in embryos served as positive control. $(H, I)$ Elevated LIT-1-GFP expression in seam cells (arrows) with m11m31 4.2 constructs in L4 N2 worms, or with wild-type 4.2 constructs in daf-12 mutant worms, respectively. Five times more animals than in $G$ had elevated expression. ( $J$ ) Low levels of LIT-1-GFP expression from 4.2 construct in vulva cells (arrow) of L4 N2 animal. $(K, L)$ Elevated LIT-1-GFP expression in vulva cells (arrows) with $\mathrm{m} 11 \mathrm{~m} 314.2$ constructs in L4 N2 worms, or with wild-type 4.2 constructs in daf-12 mutant worms, respectively. Five times more animals than in $J$ had elevated expression. In $A-L,>50$ animals per panel were examined. In $A-F$ and $J-L$, images were taken at $1000 \times$; in $G-I$, images were taken at $400 \times$. (M) Regulation of endogenous LIT-1 expression by DAF-12 in L4. LIT-1a and LIT-1b mRNAs were analyzed by qRT PCR; data were normalized to AMA-1 abundance values, which were assigned a value of 100. CAP-1, CAP-2, and RGR-1 were used as controls; various other control gene transcripts, including ACT5, RPL-19, and DPY-26, also did not change (data not shown).

GFP expression was greatly diminished in daf-12 mutant worms (rh61rh412, Fig. 4F). We conclude that DAF-12 binds to a DR5 element within 4.2 and activates LIT-1 gene expression in the C. elegans pharynx.

Strikingly, the LIT-1-GFP construct with the 4.2 $\mathrm{m} 11 \mathrm{~m} 31$ mutant response element produced increased GFP expression in seam and vulva cells at larval stage 4 (L4) in wild-type animals (Fig. 4H,K), compared with the wild-type 4.2 construct (Fig. 4G,J). We also observed elevated expression when the wild-type LIT-1-GFP construct was microinjected into the daf-12 (rh61rh412) mutant strain (Fig. 4I,L). Thus, DAF-12 may repress LIT-1 expression in seam and vulva cells in L4 animals.

We next used qRT PCR to measure endogenous LIT-1 mRNA levels in whole animals at L4. We observed a greater than twofold increased accumulation of both LIT-1 mRNA isoforms, a and b, in daf-12 (m583) mutant C. elegans (bearing a daf-12 null-like allele; Antebi et al. 2000), compared with N2 worms (Fig. 4M). These results 
Shostak et al.

strongly suggest that LIT-1 is a bona fide DAF-12 target gene.

Recovered C. elegans fragments are linked to DAF-12-regulated genes and gene clusters

Given our findings with 4.2, we determined whether other isolated fragments were linked to DAF-12-regulated genes. We measured by qRT PCR the mRNA levels of 75 C. elegans genes proximal to 28 recovered genomic fragments that exhibited DAF-12-dependent transcrip- tional activity in yeast. We examined relative gene expression in wild-type $\mathrm{N} 2$ and $d a f-12$ (m583) mutant $C$. elegans at the L4 stage, as LIT-1 gene regulation and aspects of DAF-12 function, for example, proper gonadal migration, occur in L4 (Antebi et al. 1998, 2000). We found (Fig. 5A,B) that the expression of various genes (including GST family member gst-37, Skp1 ubiquitin ligase-like skr-8 gene, Snf7 homolog-like C37C3.3, hedgehog-like grd-8, Notch pathway factor sel-8a/lag-3a, and C. elegans caveolin cav-1) was decreased by greater than twofold in the daf-12 mutant, whereas the expres-
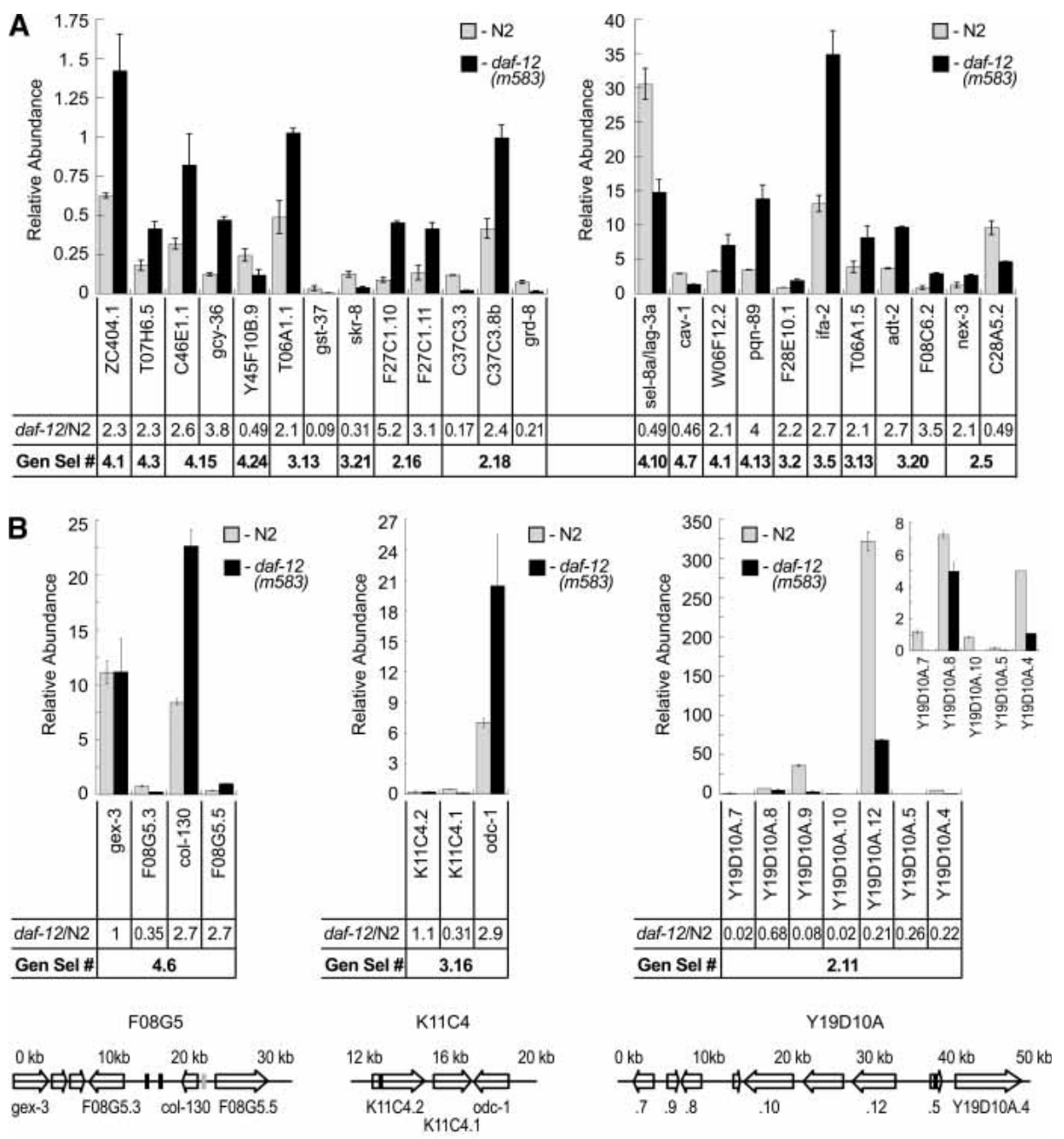

I- location of the corresponding genomic fragments $(4.6,3.16$, and 2.11 , respectively)

I - location of 3.12 genomic fragment

Figure 5. DAF-12-dependent regulation during L4 of genes linked to DAF-12 response element-containing C. elegans genomic fragments. Steady-state mRNA levels of 75 genes (listed in Supplementary Table S5), closely linked to 28 DAF-12 response elementcontaining C. elegans genomic fragments, were analyzed using qRT PCR. As in Figure 4M, data were normalized to AMA-1 abundance levels, and CAP-1, CAP-2, and RGR-1 served as controls. Expression of genes exhibiting twofold or greater DAF-12-dependent regulation at $43 \mathrm{~h}$ is shown. (A) DAF-12-dependent regulation in L4 of genes linked to DAF-12 response element-containing genomic fragments. (B) DAF-12-dependent regulation of gene clusters linked to 4.6, 3.16, and 2.11 (left, center, and right panels, respectively) response elements. In L4, gex-3 and K11C4.2 did not show DAF-12-dependent regulation; Y19D10A.8 mRNA levels were reduced less than twofold in daf-12 mutant worms. Genomic organization of each gene cluster is shown below the expression data panels, labeled according to the positions within each cosmid. Arrows represent ORFs (labeled) and their directions of transcription. Black bars denote positions of DAF-12 response elements; gray bar denotes position of a genomic fragment that failed to mediate DAF-12 dependent activity in yeast (see text). 
sion of others (including furrowed-like T07H6.5, soluble guanylyl cyclase $g c y-36$, putative mitochondrial protein C37C3.8b, prion-like $\mathrm{Q} / \mathrm{N}$ rich $p q n-89$, intermediate filament ifa-2, adt-2 protease, phosphocholine cytidylyltransferase-like F08C6.2, cuticle collagen-like col-130, UDP-glucuronosyltransferase-like F08G5.5, and ornithine decarboxylase odc-1) was increased by greater than twofold in the daf-12 mutant (see Supplemental Materials for gene references). The expression of various control genes, including CAP-1, CAP-2, RGR-1, ACT-5, RPL-19, DPY-26, and others, did not change (Fig. 4M; data not shown).

Interestingly, we found in many cases that two or more genes proximal to a particular genomic selection fragment exhibited DAF-12-dependent expression. Three examples of these DAF-12 response element-linked gene clusters are shown in Figure 5B; other clusters of DAF12-regulated genes are apparent in Figure 5A. We found that the 4.6 genomic fragment is represented in two copies $2 \mathrm{~kb}$ apart in the F08G5 cosmid on chromosome IV (Supplementary Table S1; Fig. 5B, left panel schematics). Three nearby genes examined showed DAF-12-regulated expression: F08G5.3 ORF message was down-regulated in daf-12 mutant animals, compared with wild-type $C$. elegans, whereas col-130 and F08G5.5 were up-regulated in the mutant (Fig. 5B, left panel); in contrast, gex-3 expression was unaffected by DAF-12 in these assays. In addition to 4.6, fragment 3.12 mapped to the F08G5 cosmid, just upstream of the col-130 gene and 5-7 kb from 4.6 (see Supplementary Tables S1, S2; Fig. 5B, left panel schematics). As the 3.12 genomic fragment did not mediate DAF-12-dependent transcription in yeast (Fig. 2H; Supplementary Table S2), its contribution to DAF-12dependent regulation of the nearby genes and its functional interaction with the 4.6 response element are yet to be determined.

The 3.16 fragment mapped to an intron of the K11C4.2 ORF. In L4, we found that although K11C4.2 did not display DAF-12-dependent expression, the nearby K11C4.1 (serine/threonine kinase-like) gene transcript was down-regulated in daf-12 mutant C. elegans, whereas the odc-1 message was up-regulated (Fig. 5B, center panel).

The 2.11 C. elegans genomic fragment mapped to two locations $110 \mathrm{~kb}$ apart on chromosome $\mathrm{V}$, an intron/coding region junction in the nearly identical Y19D10A.5 and C01B4.8 ORFs (Supplementary Table S3), which themselves reside within two regions of high similarity spanning $>50 \mathrm{~kb}$ each with an identical organization of predicted ORFs. In L4, we found that the expression of six of seven genes examined near the 2.11 fragmentY19D10A.7/F56A4.9 (EGF and L-domain-containing protein), Y19D10A.9/F56A4.2 (lectin C-type domain-containing protein), Y19D10A.10/F56A4.11 (anion, sugar transporter-like), Y19D10A.12/C01B4.9 (monocarboxylate transporter-like), Y19D10A.5/C01B4.8 (substrate transporter-like), and Y19D10A.4/C01B4.7 (aldose 1-epimerase family, sugar transporter-like)—was dependent on DAF-12, as daf-12 mutant worms exhibited significantly lower abundance of the corresponding mRNAs compared with $\mathrm{N} 2$ animals (Fig. 5B, right panel). The accumulation of the Y19D10A.8/F56A4.10 (anionic transporter-like) transcript differed by less than twofold (we have not determined whether these analyzed transcripts originate from the Y19D10A ORFs or C01B4/ F56A4 ORFs).

\section{Stage-specific expression patterns of DAF-12 dependent genes}

We measured by qRT PCR the transcripts from the 75 genes proximal to DAF-12 response element-containing fragments as a function of developmental stage and DAF12 activity. Specifically, we examined transcript abundance in N2 C. elegans relative to that in daf-12, daf-7, and daf-7/daf-12 double mutant worms. Under $25^{\circ} \mathrm{C}$ growth conditions, all of these animals developed normally for $24 \mathrm{~h}$, reaching L2; by $36 \mathrm{~h}$, however, the N2, daf-12, and daf-7/daf-12 C. elegans were in L3, whereas the daf-7 mutants were in L2d, an extended pre-dauer stage; daf-7 mutants molted into dauer larvae after $50 \mathrm{~h}$.

We found that UDP-glucuronosyltransferase-like F08G5.5 gene expression was down-regulated in daf-12 relative to N2 (Fig. 6A), and that the down-regulation was more pronounced during dauer induction in daf-7; expression was partially restored in daf-7/daf-12 mutants in both the L2 and L3/L2d stages. F08G5.5 was unique in displaying this specific pattern of regulation. A second subset of genes displayed up-regulation during dauer induction (daf-7) in a manner that was dependent on DAF-12: the 3.13 genomic fragment-linked gst-37 gene and 3.10-linked Y38H6C.9 (similar/associated with F-box proteins) gene; Furrowed-like T07H6.5, acyltransferase-like E03H4.7, kinase-like ZC404.9, and F28E10.1 (Fig. 6A). LIT-1b kinase expression was down-regulated in mutant L2 animals relative to wild type, but slightly up-regulated in L3/L2d with strong dependence on DAF12. Furthermore, at least four genes in a gene cluster linked to the 2.11 response element-Y19D10A.7/ F56A4.9, Y19D10A.8/F56A4.10, Y19D10A.9/F56A4.2, Y19D10A.12/C01B4.9-were strongly expressed in N2 L2 animals relative to daf-12, daf-7, and daf-7/daf-12 mutant worms (Fig. 6B).

We conclude that at least 21 DAF-12 response element-containing C. elegans genomic fragments, as defined in yeast, were linked to genes that were indeed DAF-12-regulated in C. elegans (Table 1). These 21 fragments (of 28 tested) were linked to at least 40 DAF-12 target genes, 29 of which were found in 10 genomic fragment-linked gene clusters. Moreover, DAF-12-dependent target gene regulation was developmental fate and stage specific, occurring during reproductive development and the alternative dauer program.

\section{Discussion}

Here we have described the first mechanistic characterization of DAF-12 function at the molecular level. In Vitro Genomic Selection enabled us to isolate from the 
Shostak et al.
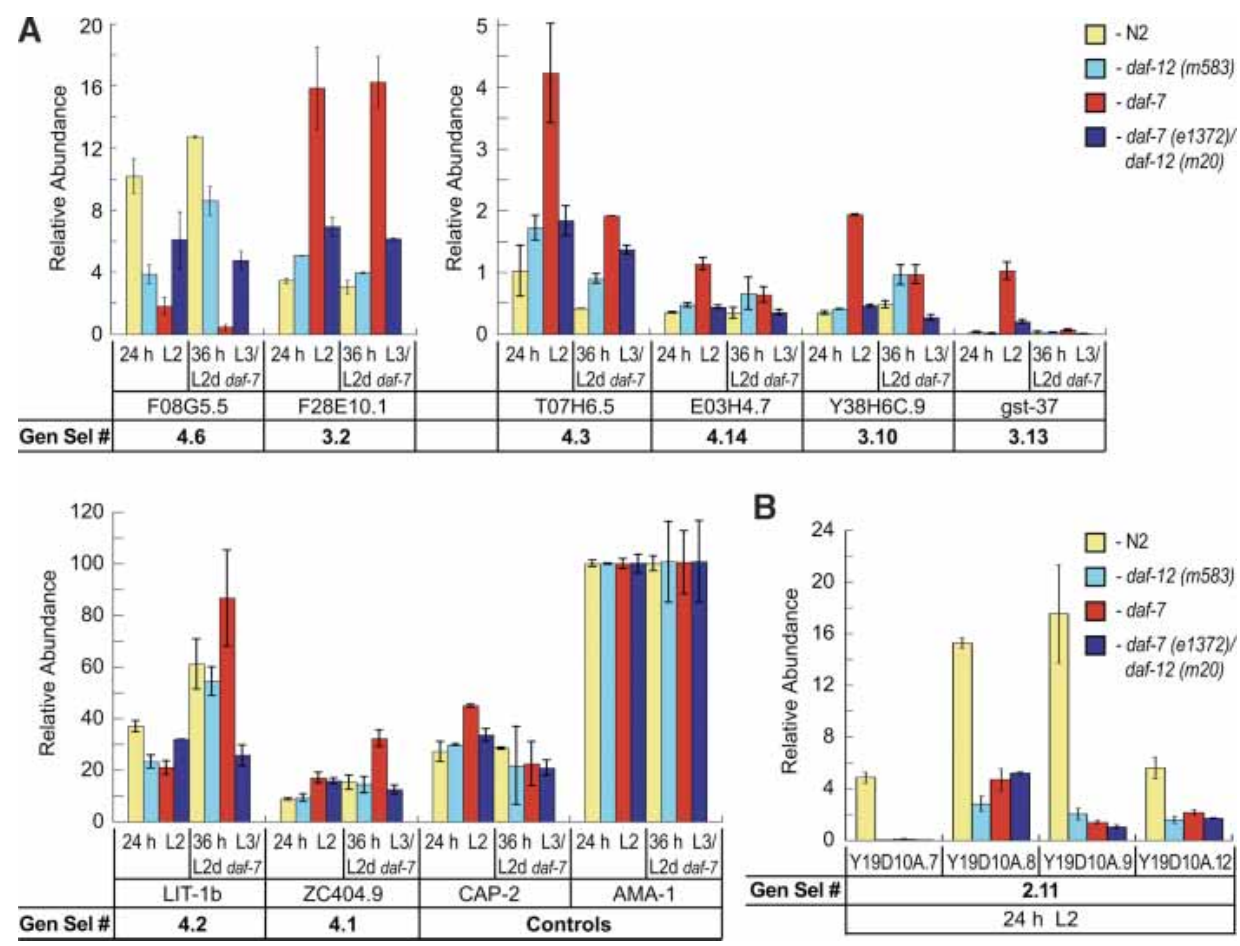

Figure 6. DAF-12-dependent regulation during dauer induction of genes linked to DAF-12 response element-containing C. elegans genomic fragments. L2 worms were harvested at $24 \mathrm{~h}$; L3 and daf-7 L2d worms were harvested at $36 \mathrm{~h}$ after plating and extracted for total RNA. daf-7(e1372) mutant worms were $100 \%$ dauers after $50 \mathrm{~h}$ at $25^{\circ} \mathrm{C}$. Steady-state mRNA levels of 75 genes (listed in Supplementary Table S5) closely linked to 28 DAF-12 response element-containing C. elegans genomic fragments were analyzed using qRT PCR. As in Figure 4M, data were normalized to AMA-1 abundance levels. Expression of genes exhibiting DAF-12 and dauerdependent regulation at 24 and/or $36 \mathrm{~h}$ is shown. (A) DAF-12 and dauer inducing condition-dependent regulation of genes linked to DAF-12 response element-containing genomic fragments in pre-dauer animals. (B) DAF-12 and dauer inducing condition-dependent regulation of DAF-12 targets in a gene cluster linked to the 2.11 response element.

C. elegans genome a series of DAF-12-binding fragments; four rounds of selection and amplification were sufficient for potent enrichment of fragments that displayed DAF-12 response element activity in yeast (see Supplementary Tables S1-S3). Using those fragments, we defined a family of high-affinity DAF-12 DNA-binding sites, characterized DAF-12 function from these sequences, and identified some primary DAF-12 target genes.

By identifying genomic sites bound directly by a regulatory factor of interest, In Vitro Genomic Selection differs from a chromatin immunoprecipitation/microarraybased method (Weinmann et al. 2002), which yields DNA fragments occupied in vivo either directly or indirectly by the factor. As such, this "ChIP on chip" approach is not as useful as a screening method for discovery of the preferred DNA-binding sites for a given regulatory factor, and to our knowledge, the method had not been applied for that purpose. ChIP on chip also requires technical resources not required by In Vitro Genomic Selection, such as an antibody directed against an epitope accessible when the target protein is assembled into many different complexes, and a whole genome microarray.

We analyzed the genomic fragments identified by our method for response element activity in yeast. Most of the active fragments contained at least one DR5 element, which was sufficient to confer DAF-12-dependent transcriptional activation. Whereas this element architecture implies that DAF-12 may act as a homodimer, a series of additional functional configurations, including heterotypic DR5 half-sites (e.g., high-affinity AGTGCA and low-affinity AGGACA), variations in half-site spacing, and direct rather than inverted repeat orientations invite speculation that DAF-12 might also heterodimerize, perhaps acting in concert with other C. elegans IRs. Such behavior is known for certain vertebrate IRs and could increase substantially the combinatorial diversity of DAF-12 target gene regulation.

Our experiments demonstrated that DAF-12 regulates LIT-1 gene expression in C. elegans, serving either as transcriptional activator or repressor, depending on developmental stage and cell type. Many potential mechanisms might explain the differential activities of DAF12. For example, the transport or metabolism of a DAF12 hormone-like ligand might be stage or cell type specific. Alternatively, the expression or activity of a DAF-12 coregulator might be selectively controlled. A third possibility is that other transcriptional regulators may bind at a lit-1 response element and differentially affect the activity of DAF-12. Indeed, examples of all three of these mechanisms have been described for mam- 
malian IRs (Funder et al. 1988; Yamamoto et al. 1992; Yoon et al. 2001).

LIT-1 encodes a MAP kinase that acts in the WNT signaling pathway to regulate cell fate during early embryogenesis and larval development (see Supplemental Materials for references). DAF-12 and LIT-1 are commonly expressed in the same cells, including pharynx, seam, and vulva, and at similar times during development. It will be interesting in future studies to pursue the relationship of DAF-12 and LIT-1. Indeed, in experiments with a temperature-sensitive lit-1 mutant (lit-1 [or131]) or with LIT-1 RNAi, we have observed protruding vulva phenotypes and defects in gonadal migration and development (see Supplementary Fig. S3; Supplementary Table S6), similar to certain daf-12 mutant alleles such as rh61 (Antebi et al. 1998, 2000). Although LIT-1 has not been shown previously to affect vulval development, WNT signaling influences that process (Eisenmann et al. 1998). Moreover, some of the lit-1 mutant phenotypes, such as defects in gonadal migration, vulval morphogenesis, and vacuoles, are reminiscent of aspects of the daf-9 mutant phenotype (Gerisch et al. 2001; Jia et al. 2002). DAF-9 is a cytochrome P450-related gene that regulates dauer formation and reproductive development and has been proposed to function in the metabolism of a potential DAF-12 ligand.

We defined candidate DAF-12 response elements as those selected genomic fragments that conferred DAF12 -activated expression in a yeast reporter assay. This criterion likely identifies only a subset of bona fide DAF12 response elements, as fragments lacking activity in yeast might well be functional in C. elegans. It is intriguing in this regard that one of the selected fragments inactive in yeast maps to the coding region of $s d f-9$, which affects dauer formation (Ohkura et al. 2003); it will be interesting to determine if $s d f-9$ is indeed regulated by DAF-12.

In this study, we surveyed candidate target gene expression by measuring steady-state mRNA levels in whole animals. This is a simple but insensitive assay, as DAF-12-dependent transcriptional regulation of target genes is likely to be cell and stage specific. Moreover, a target gene might be up-regulated in one cell and downregulated in another, as seen with the LIT-1 GFP reporter, such that even robust regulation might be masked entirely. Nevertheless, our whole-animal, realtime PCR analyses allowed us rapidly to screen many candidates and to identify 40 genes exhibiting DAF-12dependent regulation (see Tables 1,3 ).

It will be illuminating in future work to define DAF-12 target gene regulation at the cell-specific and stage-specific levels. Already, we have evidence for such refinements. For instance, F08G5.5 expression was elevated, relative to wild type, in L4 stage daf-12 mutant animals, whereas expression was down-regulated in L2 and L3 under reproductive conditions and elevated under dauer-inducing conditions. Meanwhile, expression of a group of genes (including Y19D10A.7, Y19D10A.9, Y19D10A.12) in the Y19D10A cosmid was highly dependent on DAF-12 in both the L4 and L2 stages dur- ing reproductive development but not in the dauer program.

Identification of DAF-12 target genes, together with a glimpse at their developmental expression patterns, invites speculation on their physiological roles. For example, the UDP-glucuronosyltransferase-like F08G5.5 gene might serve as a checkpoint whose expression and function ensures reproductive development, whereas its absence provokes dauer formation. Similarly, the DAF12 target genes on the Y19D10A cosmid may provide a signaling function during reproductive development together with their likely roles in metabolic regulation. A group of genes, including F28E10.1, T07H6.5, E03H4.7, Y38H6C.9, gst-37, and ZC404.9, displays DAF-12-dependent up-regulation during dauer induction (Fig. 6A), conceivably triggering early aspects of dauer formation. Indeed, we found that reducing ZC404.9 function by RNAi compromised the ability of $\mathrm{N} 2$ worms to form transient dauers at high $\left(27^{\circ} \mathrm{C}\right)$ temperature (see Supplementary Table S6).

Numerous DAF-12 targets display putative metabolic roles and dauer program-dependent regulation, perhaps consistent with the shift from aerobic to anaerobic metabolism during dauer formation (Holt and Riddle 2003). During reproductive development in L4, we observed DAF-12-dependent expression of the Notch pathway factor se1-8/lag-3 (see Supplemental Materials for reference), which functions in vulval and gonadal development, potentially mediating DAF-12 function in these processes. DAF-12-dependent regulation of Skp1 ubiquitin ligase-like $s k r-8$ gene expression may reflect a role for ubiquitin-mediated protein degradation in DAF-12 action. Indeed, skr-8 affects C. elegans lifespan and is regulated by insulin signaling (Murphy et al. 2003), implying that skr-8 may be downstream of a convergence of the DAF-12 and insulin pathways, where the insulin signaling mediator DAF-16 interacts physically with DAF-12 (Dowell et al. 2003). Finally, DAF-12-dependent regulation of caveolin expression is intriguing, as caveolin is critical for cellular function and developmental processes in C. elegans and other organisms (Sternberg and Schmid 1999; van Deurs et al. 2003), regulating, for example, TGF- $\beta$ signaling in mammalian cells (Razani et al. 2001; Di Guglielmo et al. 2003) and participating in cholesterol transport; $c a v-1$, similarly to $s k r-8$, is a target of insulin signaling in C. elegans (Murphy et al. 2003). Thus, numerous DAF-12 target genes can be fitted logically into regulatory networks governing aspects of $C$. elegans reproductive development and dauer formation.

In metazoans such as Drosophila and humans, cis-acting elements that modulate transcription can reside upstream, within, or downstream of the regulated genes, and can be very remote, up to hundreds of kilobases away (Levine and Tjian 2003). In C. elegans, few such elements have been characterized (Zhang and Emmons 2000). In this study, we found DAF-12 response elements upstream, in introns and coding regions, and downstream of genes under DAF-12 control (see Supplementary Tables S1-S3; Figs. 4-6). The substantially higher density of genes within the C. elegans genome, relative 
Shostak et al.

Table 3. DAF-12 target genes

\begin{tabular}{|c|c|c|c|}
\hline $\begin{array}{l}\text { Genomic } \\
\text { selection } \\
\text { fragment }\end{array}$ & OFR/gene designation & Gene identity/similarity & Putative function \\
\hline 4.6 & F08G5.5 & $\begin{array}{l}\text { UDP-glucuronosyltransferase and lectin C-type } \\
\text { domains }\end{array}$ & Metabolism/biosynthesis \\
\hline 4.14 & $\mathrm{E} 03 \mathrm{H} 4.7$ & Acyltransferase-like & Metabolism/biosynthesis \\
\hline 3.13 & gst-37 & Glutathione S-transferase (GST) family member & Metabolism/biosynthesis \\
\hline 3.16 & odc-1 & Ornithine decarboxylase & Metabolism/biosynthesis \\
\hline 3.20 & F08C6.2 & $\begin{array}{l}\text { Phosphocholine cytidylyltransferase-phospholipid } \\
\text { biosynthesis }\end{array}$ & Metabolism/biosynthesis \\
\hline 2.11 & Y19D10A.10 (F56A4.11-like) & Solute carrier anion, sugar transporter-like & Metabolism/biosynthesis \\
\hline 2.11 & Y19D10A.12 (C01B4.9-like) & Monocarboxylate transporter-like & Metabolism/biosynthesis \\
\hline 2.11 & Y19D10A.4 (C01B4.7-like) & $\begin{array}{l}\text { Aldose 1-epimerase family member, sugar transporter } \\
\text { domain }\end{array}$ & Metabolism/biosynthesis \\
\hline 2.11 & Y19D10A.5 (C01B4.8-like) & Substrate transporter-like & Metabolism/biosynthesis \\
\hline 2.11 & Y19D10A.8 (F56A4.10-like) & Similar to anionic transporter NPT1, sialin & Metabolism/biosynthesis \\
\hline 2.11 & Y19D10A.9 (F56A4.2) & $\begin{array}{l}\text { Lectin C-type domain-containing protein, sugar } \\
\text { binding }\end{array}$ & Metabolism/biosynthesis \\
\hline 2.18 & $\mathrm{C} 37 \mathrm{C} 3.8 \mathrm{~b}$ & Putative mitochondrial protein & Metabolism/biosynthesis \\
\hline 2.18 & C37C3.3 & $\begin{array}{l}\text { Snf7 (protein sorting and transport, metabolism in } \\
\text { yeast) homolog-like }\end{array}$ & Protein processing \\
\hline 3.20 & adt-2 & $\begin{array}{l}\text { ADAMTS-like protease; reprolysin and } \\
\text { thrombospondin type I domains }\end{array}$ & Protein processing \\
\hline 3.21 & skr-8 & Skp1 (ubiquitin ligase complex component)-like & Protein processing \\
\hline 4.1 & ZC404.9 & Mitogen-activated kinase kinase kinase kinase-like & Signaling \\
\hline 4.2 & lit-1 & Nemo-like kinase-MAP kinase and Wnt signaling & Signaling \\
\hline 4.15 & gcy-36 & Soluble guanylyl cyclase & Signaling \\
\hline 3.16 & $\mathrm{~K} 11 \mathrm{C} 4.1$ & $\begin{array}{l}\text { Similar to serine/threonine kinase, tau-tubulin and } \\
\text { casein kinase-like }\end{array}$ & Signaling \\
\hline 2.5 & nex-3 & Annexin-phospholipid binding & Signaling \\
\hline 2.11 & Y19D10A.7 (F56A4.9-like) & $\begin{array}{l}\text { Epidermal growth factor-like, L domain-containing } \\
\text { protein }\end{array}$ & Signaling \\
\hline 4.7 & cav-1 & Caveolin & Signaling/structure \\
\hline 4.10 & sel-8a/lag-3a & Putative transcription factor in the Notch pathway & Signaling/transcription \\
\hline 4.3 & T07H6.5 & $\begin{array}{l}\text { Sushi repeat protein, similar to furrowed (Drosophila } \\
\text { melanogaster) }\end{array}$ & Structure \\
\hline 4.6 & col-130 & Cuticle collagen-like & Structure \\
\hline 3.5 & ifa-2 & Intermediate filament & Structure \\
\hline 4.1 & ZC404.1 & Unknown function & Unknown function \\
\hline 4.2 & W06F12.2 & Putative N-myristoylated protein family member & Unknown function \\
\hline 4.6 & F08G5.3 & $\begin{array}{l}\text { Uncharacterized (some similarity to Drosophila } \\
\text { melanogaster cdc37) }\end{array}$ & Unknown function \\
\hline 4.13 & pqn-89 & Prion-like Q/N-rich domain protein & Unknown function \\
\hline 4.15 & C46E1.1 & Low similarity to brevinin-1E precursor & Unknown function \\
\hline 4.24 & Y45F10B.9 & SMC and RING domains-containing protein & Unknown function \\
\hline 3.2 & F28E10.1 & Unknown function & Unknown function \\
\hline 3.10 & Y38H6C.9 & Similar/associated with F-box proteins & Unknown function \\
\hline 3.13 & T06A1.1 & Unknown function & Unknown function \\
\hline 3.13 & T06A1.5 & Unknown function & Unknown function \\
\hline 2.5 & C28A5.2 & Unknown function & Unknown function \\
\hline 2.16 & $\mathrm{~F} 27 \mathrm{C} 1.10$ & Unknown function & Unknown function \\
\hline 2.16 & $\mathrm{~F} 27 \mathrm{C} 1.11$ & $\begin{array}{l}\text { Doublecortin and IQ calmodulin-binding region and } \\
\text { lipoxygenase, LH2 domain containing protein }\end{array}$ & Unknown function \\
\hline 2.18 & grd-8 & Groundhog (hedgehog-like family) protein 8 & Unknown function \\
\hline
\end{tabular}

to Drosophila or mammals, implies that C. elegans harbors mechanisms that tightly couple DAF-12 response elements, for example, to cognate target genes, and exclude nearby nontarget genes from influence by DAF-12. Conceivably, C. elegans uses strategies proposed to function in other metazoans, such as insulators, proximal promoter-enhancer tethering, and gene competition (Levine and Tjian 2003), or instead has evolved other mechanisms.

We found that $C$. elegans genomic fragments displaying DAF-12 response element activity in yeast were commonly tightly linked to DAF-12-regulated gene clus- 
ters, ranging from at least two to at least seven genes per cluster (the absolute dimensions of the clusters, and their developmental stage specificity, have not been fully defined). Interestingly, clustering of C. elegans muscle-specific genes has been observed, prompting the suggestion that an "active chromatin" domain or a common regulatory element might explain the findings (Roy et al. 2002). Our finding of clusters in which individual genes appear to be regulated differentially (i.e., DAF-12 activated or repressed within the same cluster) seems to argue against the simplest versions of these mechanisms. This degree of complexity is not unique, however, because bacteriophage studies established more than 30 years ago that a single regulator, acting from a single response element, could regulate one gene positively and another negatively (Reichardt and Kaiser 1971; Johnson et al. 1979). The fact that we were unable to identify additional DAF-12-binding sites by computational analysis (FUZZNUC [EMBOSS]: http://bioweb. pasteur.fr/seqanal/interfaces/fuzznuc.html) of sequences within the clusters may indicate that a single response element exerts primary control over multiple genes. It will be interesting to determine if any of the genomic fragments harbor "locus control regions", which have been shown in Drosophila and vertebrates to impose global regulation over clusters of related genes (Grosveld 1999; Pavlova et al. 1999; Lee et al. 2003).

Although response elements and target genes for IRs have been identified in other metazoans, our findings are significant for several reasons: First, we established proof of principle for the notion that biologically functional genetic elements can be isolated from metazoan genomic DNA using a purified DBD. Second, C. elegans encodes 284 IR genes (Sluder and Maina 2001), far more than any other known organism (c.f., 48 in the human genome [Maglich et al. 2001], 21 in D. melanogaster [Rubin et al. 2000]); within C. elegans, DAF-12 is closely related to two other receptors. It will be illuminating to determine roles for the many $C$. elegans regulators and to assess functional relationships within the DAF-12 subfamily. Finally, it may prove possible in C. elegans, with its sequenced genome, defined cell lineage, powerful genetics, and other experimental advantages, to describe the complete regulatory network for a global effector such as DAF-12; a full appraisal of the "physiological spectrum" of a regulator would enrich our understanding of regulatory evolution and the principles that define regulatory networks.

In Vitro Genomic Selection seems potentially applicable to any DNA-binding protein for which the functional DBD can be purified, yielding naturally occurring DNA-binding sites in their genomic context. Although minimal DNA binding sequences can be derived by random selection (Blackwell and Weintraub 1990), the biological significance of such sequences is unknown. Similarly, response element and target gene identification through sequential random selection and computational genomic analysis is a useful approach for some regulators (Berman et al. 2002) but may be less so for IRs, which typically bind to response elements containing relatively few binding sites and high half-site degeneracy. Clearly, the genomic context of factor binding is a critical component of factor activity (Lefstin and Yamamoto 1998; Yamamoto et al. 1998; Rogatsky et al. 2002), and factor-binding sites typically reside within "composite response elements" (Yamamoto et al. 1992), which include sites for multiple factors, and which nucleate assembly of complexes whose composition and action depend strongly on the precise sites within the element. Fragments isolated by In Vitro Genomic Selection allow protein binding and activity to be assessed either in isolation or in a functional combinatorial context. Finally, the response elements elucidated by In Vitro Genomic Selection provide "tags" to genes that are regulated by the factor of interest, thus leading to identification of direct transcriptional target genes.

\section{Materials and methods}

\section{In Vitro Genomic Selection}

Two micrograms of purified (see Methods in Supplemental Materials) recombinant Flag-tagged DAF-12 DBD was immobilized on $30 \mu \mathrm{L}$ of anti-Flag M2 affinity matrix (Sigma) by incubation for $90 \mathrm{~min}$ at $4^{\circ} \mathrm{C}$ in $150 \mu \mathrm{L}$ of TBS-2 buffer $(50 \mathrm{mM}$ Tris at $\mathrm{pH}$ 7.4, $150 \mathrm{mM} \mathrm{NaCl}, 10 \mu \mathrm{M} \mathrm{Zn}\left(\mathrm{C}_{2} \mathrm{H}_{3} \mathrm{O}_{2}\right)_{2}, 0.1 \mathrm{mM}$ EDTA). The matrix was then washed with TBS-2 buffer containing $1 \mathrm{M}$ $\mathrm{NaCl}$, followed by two washes with the binding buffer $(20 \mathrm{mM}$ HEPES at $\mathrm{pH} 7.9,8 \%$ glycerol, $10 \mathrm{mM} \mathrm{MgCl}_{2}, 100 \mathrm{mM} \mathrm{KCl}, 10$ $\left.\mu \mathrm{M} \mathrm{Zn}\left(\mathrm{C}_{2} \mathrm{H}_{3} \mathrm{O}_{2}\right)_{2}\right)$. All washes were performed at $4^{\circ} \mathrm{C}$ for $5 \mathrm{~min}$ on a nutator. Immobilized DAF-12 DBD was then incubated with $5 \mu \mathrm{g}$ of C. elegans genomic DNA digested with 16 units of Sau3AI restriction endonuclease (NEB) overnight, in $150 \mu \mathrm{L}$ of binding buffer for $25 \mathrm{~min}$ at room temperature on a nutator. Protein-DNA bead complexes were washed with $150 \mu \mathrm{L}$ of the binding buffer for $5 \mathrm{~min}$ on nutator at $4^{\circ} \mathrm{C}$, followed by a wash with binding buffer containing $250 \mathrm{mM} \mathrm{KCl}$ and a third wash containing $500 \mathrm{mM} \mathrm{KCl}$. DAF-12-bound DNA was eluted from the beads with $250 \mu \mathrm{L}$ of the binding buffer containing $1 \mathrm{M} \mathrm{KCl}$ (10 min with $150 \mu \mathrm{L}$ followed by 15 min with $100 \mu \mathrm{L}$; incubations on a nutator).

TE $(250 \mu \mathrm{L})$ was added to the eluate and the DNA was phenol/ chloroform-extracted and precipitated in the presence of $5 \mu \mathrm{g}$ of glycogen; the pellet was redissolved in $12 \mu \mathrm{L}$ of $\mathrm{H}_{2} \mathrm{O}$. Either 1 or 0.1 pmole of double-stranded NotISau3A oligonucleotide (hybridized 5'-GGGGCGGCCGC-3' to 5'-P-GATCGCGGCCGC CCC-3') was ligated to $10 \mu \mathrm{L}$ of DNA with $0.5 \mu \mathrm{L}$ of T4 DNA Ligase (NEB) in $20 \mu \mathrm{L}$ total volume. Two microliters of the ligation mixture was used as template in a $100-\mu \mathrm{L}$ first PCR reaction $(1.4 \mu \mathrm{L}$ of Vent DNA Polymerase [NEB], 400 pmole of NotISau3A PCR+ primer [5'-GGGGCGGCCGCGATC-3'], 1× of Thermal Pol Buffer [NEB], $250 \mu \mathrm{M}$ dNTPs, $0.5 \mathrm{mM}$ extra $\mathrm{MgSO}_{4}$; PCR program: [1] $92^{\circ} \mathrm{C}$ for $4 \mathrm{~min}$, [2] $92^{\circ} \mathrm{C}$ for $1 \mathrm{~min},[3]$ $57^{\circ} \mathrm{C}$ for $45 \mathrm{sec},[4] 72^{\circ} \mathrm{C}$ for $2 \mathrm{~min}$, [5] GoTo (2) 28 times, [6] $72^{\circ} \mathrm{C}$ for $5 \mathrm{~min},[7] 4^{\circ} \mathrm{C}$ ).

Amplified DNA was purified using Qiaquick columns (Qiagen) and $2 \mu \mathrm{g}$ of DNA was used for subsequent rounds of binding, performed as described earlier, except a $250-\mathrm{mM} \mathrm{KCl}$ wash was used instead of the $500-\mathrm{mM} \mathrm{KCl}$ wash. After each binding/ elution round, PCR was performed for a total of four rounds. After the second, third, or fourth PCR, purified DNA was digested with NotI restriction endonuclease (NEB) and subcloned into the NotI site of pBluescriptIIKS+ vector (Stratagene) for sequencing and analysis. 


\section{qRT PCR analysis of C. elegans genomic fragments}

After each round of In Vitro Genomic Selection and amplification, the product mixture was analyzed for relative abundance of individual C. elegans genomic fragments using qRT PCR. Each $50 \mu \mathrm{L}$ qRT PCR reaction contained $0.5 \mathrm{ng}$ of Sau3A-digested product, $1.25 \mathrm{U}$ of Taq DNA polymerase (Invitrogen), 1.5 $\mathrm{mM} \mathrm{MgCl} 2,125 \mu \mathrm{M}$ dNTP mix, $0.6 \mu \mathrm{M}$ of each primer (listed in Supplementary Table S4 for each genomic fragment), and $0.2 \times$ SYBR Green I dye (Molecular Probes) in $1 \times$ Taq buffer (Invitrogen). qRT PCR was performed in triplicate with an Opticon-2 DNA Engine (MJ Research) and analyzed using the $\delta \delta \mathrm{Ct}$ method. After 37 cycles, a melting curve of the product was generated between $70^{\circ} \mathrm{C}$ and $94^{\circ} \mathrm{C}$, reading every $0.2^{\circ} \mathrm{C}$. The data were normalized to the values of amplification from Sau3A-digested total C. elegans genomic DNA for each genomic selection and control fragment.

\section{Fluorescence anisotropy}

Fluorescein-labeled double-stranded oligonucleotides, either 1 or $10 \mathrm{nM}$ of DR5tt and DR5gt (Fig. 3C), in $2 \mathrm{~mL}$ of $20 \mathrm{mM}$ Tris (pH 7.4), $100 \mathrm{mM} \mathrm{KCl}$, and $5 \mathrm{mM} \mathrm{MgCl}_{2}$, were used for fluorescence anisotropy measurements with GST-DAF-12 DBD (see Methods in Supplemental Materials). Excitation was performed at $485-\mathrm{nm}$ wavelength and emission was monitored at $515 \mathrm{~nm}$ using a Photon Technologies International fluorometer. Anisotropy calculations and $\mathrm{K}_{\mathrm{d}}$ determinations by curve fitting were performed as previously described (Gill et al. 1991; Jagath et al. 1998) using KaleidaGraph 3.51 (Synergy Software).

\section{Transcriptional reporter and target gene expression assays}

See Methods in Supplemental Materials for the yeast transcriptional reporter assay. For the C. elegans transcriptional reporter assay, the wild-type or $\mathrm{m} 11 \mathrm{~m} 31$ mutant 4.2 fragment was subcloned upstream of a minimal pes-10 promoter driving GFP expression in pPD97.78 vector (plasmids pYSCR0001 and pYSCR0002, respectively). Fifty nanograms per microliter of the constructs were microinjected into wild-type $\mathrm{N} 2$ or daf-12 mutant rh61rh412 C. elegans with $50 \mathrm{ng} / \mathrm{\mu L}$ rol-6 marker. daf-12 (rh61rh412) is a loss-of-function class 3 mutant allele characterized by dauer-defective phenotype and impenetrant extragonadal heterochronic phenotype (Antebi et al. 2000).

For target gene GFP expression assays, the wild-type or $\mathrm{m} 11 \mathrm{~m} 31$ mutant LIT-1b genomic fragment (nucleotides $4527-$ 8561 from W06F12 cosmid) was subcloned into pPD95.67 vector to make an in-frame LIT-1-GFP fusion (plasmids pYSCR0003 and pYSCR0004, respectively). Ten nanograms per microliter of the constructs were microinjected in wild-type N2 or daf-12 mutant rh61rh412 C. elegans with $50 \mathrm{ng} / \mathrm{\mu L}$ rol-6 marker. pPD97.78 and pPD95.67 vectors were generously provided by Andy Fire.

\section{qRT PCR analysis of putative DAF-12 target gene expression}

Wild-type N2 and daf-12(m583) mutant C. elegans strains were grown at $20^{\circ} \mathrm{C}$, and daf-7(e1372) and daf-7(e1372)/daf-12(m20) mutant strains were grown at $15^{\circ} \mathrm{C}$ or $20^{\circ} \mathrm{C}$ on normal NGMlight or $8 \times$ tryptone plates pregrown with OP50 bacteria. Similar to daf-12 (rh61rh412), daf-12(m583) and daf-12(m20) are lossof-function class 3 mutant alleles characterized by dauer-defective phenotype and impenetrant extragonadal heterochronic phenotype (Antebi et al. 2000). daf-7(e1372) form constitutive dauers at nonpermissive temperatures $\left(\geq 20^{\circ} \mathrm{C}\right)$, and daf7(e1372)/daf-12(m20) double mutants are dauer defective at all temperatures. daf-7(e1372) and daf-7(e1372)/daf-12(m20) C. elegans stains were generously provided by Pamela Larsen (University of Texas, San Antonio). Worms were growth synchronized by bleaching followed by harvest of embryos. Embryos were plated on NGM-light plates with OP50 bacterial layer and grown at $25^{\circ} \mathrm{C}$; larvae were harvested at $24 \mathrm{~h}$ for L2, $36 \mathrm{~h}$ for L3, and $43 \mathrm{~h}$ for L4, and washed three times in $1 \times \mathrm{M} 9$ buffer before RNA isolation. Total RNA from $>50,000$ worms was isolated using TRI Reagent (MRC, Inc.) with subsequent purification and DNase I treatment using RNeasy-Mini kit (Qiagen). Random-primed cDNA was prepared from $3 \mu \mathrm{g}$ of total RNA using the ProtoScript first-strand cDNA synthesis kit (NEB). Each 50 $\mu \mathrm{L}$ qRT PCR reaction was as described earlier, except it contained $120 \mathrm{ng}$ of cDNA and $1 \mu \mathrm{M}$ of each primer (listed in Supplementary Table S5 for each target gene). qRT PCR was performed in duplicate as described earlier. RNA polymerase II large subunit AMA-1 gene was used as an internal control for data normalization. After 37 or 45 cycles, a melting curve of a product was generated as described earlier. AMA-1 and RGR-1 primers were designed by Wally Wang. The data shown are representative of two to five independent worm growths and RNA isolations.

\section{Acknowledgments}

We are grateful to Andy Fire, Pamela Larsen, and Wally Wang for materials; Susan Mango for information prior to publication; and Cori Bargmann's and Cynthia Kenyon's labs for sharing equipment and expertise. We thank members of Yamamoto lab for stimulating discussions, and Cori Bargmann, Brian Black, Eric Bolton, Alan Frankel, Cynthia Kenyon, Wendell Lim, Sebastiaan Meijsing, Coleen Murphy, and Inez Rogatsky for helpful and clarifying critiques of the manuscript. This work was supported by grants from NIH and NSF; Y.S. held an NSF Graduate Research Fellowship; M.R.V.G. was a postdoctoral fellow of the Helen Hay Whitney Foundation.

\section{References}

Antebi, A., Culotti, J.G., and Hedgecock, E.M. 1998. daf-12 regulates developmental age and the dauer alternative in Caenorhabditis elegans. Development 125: 1191-1205.

Antebi, A., Yeh, W.H., Tait, D., Hedgecock, E.M., and Riddle, D.L. 2000. daf-12 encodes a nuclear receptor that regulates the dauer diapause and developmental age in C. elegans. Genes \& Dev. 14: 1512-1527.

Asahina, M., Ishihara, T., Jindra, M., Kohara, Y., Katsura, I., and Hirose, S. 2000. The conserved nuclear receptor Ftz-F1 is required for embryogenesis, moulting and reproduction in Caenorhabditis elegans. Genes Cells 5: 711-723.

Ashburner, M. 1990. Puffs, genes, and hormones revisited. Cell 61: $1-3$.

Berman, B.P., Nibu, Y., Pfeiffer, B.D., Tomancak, P., Celniker, S.E., Levine, M., Rubin, G.M., and Eisen, M.B. 2002. Exploiting transcription factor binding site clustering to identify cis-regulatory modules involved in pattern formation in the Drosophila genome. Proc. Natl. Acad. Sci. 99: 757-762.

Blackwell, T.K. and Weintraub, H. 1990. Differences and similarities in DNA-binding preferences of MyoD and E2A protein complexes revealed by binding site selection. Science 250: 1104-1110.

Carmi, I., Kopczynski, J.B., and Meyer, B.J. 1998. The nuclear hormone receptor SEX-1 is an X-chromosome signal that determines nematode sex. Nature 396: 168-173. 
Chawla, A., Repa, J.J., Evans, R.M., and Mangelsdorf, D.J. 2001. Nuclear receptors and lipid physiology: Opening the X-files. Science 294: 1866-1870.

Di Guglielmo, G.M., Le Roy, C., Goodfellow, A.F., and Wrana, J.L. 2003. Distinct endocytic pathways regulate TGF- $\beta$ receptor signalling and turnover. Nat. Cell Biol. 5: 410-421.

Dowell, P., Otto, T.C., Adi, S., and Lane, M.D. 2003. Convergence of PPARg and Foxol signaling pathways. J. Biol. Chem. 278: 45485-45491.

Eisenmann, D.M., Maloof, J.N., Simske, J.S., Kenyon, C., and Kim, S.K. 1998. The $\beta$-catenin homolog BAR-1 and LET-60 Ras coordinately regulate the Hox gene lin-39 during Caenorhabditis elegans vulval development. Development 125: 3667-3680.

Ellington, A.D. and Szostak, J.W. 1990. In vitro selection of RNA molecules that bind specific ligands. Nature 346: 818822.

Fisk, G.J. and Thummel, C.S. 1995. Isolation, regulation, and DNA-binding properties of three Drosophila nuclear hormone receptor superfamily members. Proc. Natl. Acad. Sci. 92: 10604-10608.

Freedman, L.P., Arce, V., and Perez Fernandez, R. 1994. DNA sequences that act as high affinity targets for the vitamin D3 receptor in the absence of the retinoid X receptor. Mol. Endocrinol. 8: 265-273.

Funder, J.W., Pearce, P.T., Smith, R., and Smith, A.I. 1988. Mineralocorticoid action: Target tissue specificity is enzyme, not receptor, mediated. Science 242: 583-585.

Gaudet, J. and Mango, S.E. 2002. Regulation of organogenesis by the Caenorhabditis elegans FoxA protein PHA-4. Science 295: 821-825.

Gems, D., Sutton, A.J., Sundermeyer, M.L., Albert, P.S., King, K.V., Edgley, M.L., Larsen, P.L., and Riddle, D.L. 1998. Two pleiotropic classes of daf-2 mutation affect larval arrest, adult behavior, reproduction and longevity in Caenorhabditis elegans. Genetics 150: 129-155.

Gerisch, B., Weitzel, C., Kober-Eisermann, C., Rottiers, V., and Antebi, A. 2001. A hormonal signaling pathway influencing C. elegans metabolism, reproductive development, and life span. Dev. Cell 1: 841-851.

Gill, S.C., Weitzel, S.E., and von Hippel, P.H. 1991. Escherichia coli $\sigma 70$ and NusA proteins. I. Binding interactions with core RNA polymerase in solution and within the transcription complex. J. Mol. Biol. 220: 307-324.

Gissendanner, C.R. and Sluder, A.E. 2000. nhr-25, the Caenorhabditis elegans ortholog of $\mathrm{ftz}-\mathrm{f} 1$, is required for epidermal and somatic gonad development. Dev. Biol. 221: 259272.

Godowski, P.J., Rusconi, S., Miesfeld, R., and Yamamoto, K.R. 1987. Glucocorticoid receptor mutants that are constitutive activators of transcriptional enhancement. Nature 325: 365 368.

Grosveld, F. 1999. Activation by locus control regions? Curr. Opin. Genet. Dev. 9: 152-157.

Holt, S.J. and Riddle, D.L. 2003. SAGE surveys C. elegans carbohydrate metabolism: Evidence for an anaerobic shift in the long-lived dauer larva. Mech. Ageing Dev. 124: 779-800.

Hsin, H. and Kenyon, C. 1999. Signals from the reproductive system regulate the lifespan of C. elegans. Nature 399: 362366.

Huang, W., Shostak, Y., Tarr, P., Sawyers, C., and Carey, M. 1999. Cooperative assembly of androgen receptor into a nucleoprotein complex that regulates the prostate-specific antigen enhancer. J. Biol. Chem. 274: 25756-25768.

Jagath, J.R., Rodnina, M.V., Lentzen, G., and Wintermeyer, W. 1998. Interaction of guanine nucleotides with the signal rec- ognition particle from Escherichia coli. Biochemistry 37: 15408-15413.

Jia, K., Albert, P.S., and Riddle, D.L. 2002. DAF-9, a cytochrome P450 regulating C. elegans larval development and adult longevity. Development 129: 221-231.

Johnson, A.D., Meyer, B.J., and Ptashne, M. 1979. Interactions between DNA-bound repressors govern regulation by the $\lambda$ phage repressor. Proc. Natl. Acad. Sci. 76: 5061-5065.

Kinzler, K.W. and Vogelstein, B. 1989. Whole genome PCR: Application to the identification of sequences bound by gene regulatory proteins. Nucleic Acids Res. 17: 3645-3653.

Kostrouchova, M., Krause, M., Kostrouch, Z., and Rall, J.E. 1998. CHR3: A Caenorhabditis elegans orphan nuclear hormone receptor required for proper epidermal development and molting. Development 125: 1617-1626.

Larsen, P.L., Albert, P.S., and Riddle, D.L. 1995. Genes that regulate both development and longevity in Caenorhabditis elegans. Genetics 139: 1567-1583.

Lee, G.R., Fields, P.E., Griffin, T.J., and Flavell, R.A. 2003. Regulation of the Th2 cytokine locus by a locus control region. Immunity 19: 145-153.

Lefstin, J.A. and Yamamoto, K.R. 1998. Allosteric effects of DNA on transcriptional regulators. Nature 392: 885-888.

Levine, M. and Tjian, R. 2003. Transcription regulation and animal diversity. Nature 424: 147-151.

Lindblom, T.H., Pierce, G.J., and Sluder, A.E. 2001. A C. elegans orphan nuclear receptor contributes to xenobiotic resistance. Curr. Biol. 11: 864-868.

Maglich, J.M., Sluder, A., Guan, X., Shi, Y., McKee, D.D., Carrick, K., Kamdar, K., Willson, T.M., and Moore, J.T. 2001. Comparison of complete nuclear receptor sets from the human, Caenorhabditis elegans and Drosophila genomes. Genome Biol. 2: RESEARCH0029.

Much, J.W., Slade, D.J., Klampert, K., Garriga, G., and Wightman, B. 2000. The fax-1 nuclear hormone receptor regulates axon pathfinding and neurotransmitter expression. Development 127: 703-712.

Murphy, C.T., McCarroll, S.A., Bargmann, C.I., Fraser, A., Kamath, R.S., Ahringer, J., Li, H., and Kenyon, C. 2003. Genes that act downstream of DAF-16 to influence the lifespan of Caenorhabditis elegans. Nature 424: 277-283.

Ohkura, K., Suzuki, N., Ishihara, T., and Katsura, I. 2003. SDF-9, a protein tyrosine phosphatase-like molecule, regulates the L3/dauer developmental decision through hormonal signaling in C. elegans. Development 130: 3237-3248.

Pavlova, G.V., Churikov, H.A., Korochkin, L.I., Ponomarenko, N.A., and Shostak, N.G. 1999. [Detection of a new tissuespecific enhancer in the ct 6 region of the regulatory region of the drosophila cut locus]. Genetika 35: 412-416.

Payvar, F., Firestone, G.L., Ross, S.R., Chandler, V.L., Wrange, O., Carlstedt-Duke, J., Gustafsson, J.A., and Yamamoto, K.R. 1982. Multiple specific binding sites for purified glucocorticoid receptors on mammary tumor virus DNA. J. Cell. Biochem. 19: 241-247.

Rastinejad, F. 1998. Structure and function of the steroid and nuclear receptor DNA binding domain. In Molecular biology of steroid and nuclear hormone receptors (ed. L.P. Freedman), pp. 105-131. Birkhauser, Boston.

Razani, B., Zhang, X.L., Bitzer, M., von Gersdorff, G., Bottinger, E.P., and Lisanti, M.P. 2001. Caveolin-1 regulates transforming growth factor (TGF)- $\beta$ /SMAD signaling through an interaction with the TGF- $\beta$ type I receptor. I. Biol. Chem. 276: 6727-6738.

Reichardt, L. and Kaiser, A.D. 1971. Control of $\lambda$ repressor synthesis. Proc. Natl. Acad. Sci. 68: 2185-2189.

Riddle, D.L. and Albert, P.S. 1997. Genetic and environmental 
regulation of dauer larva development. In C. elegans II (eds. D.L. Riddle et al.), pp. 739-768. Cold Spring Harbor Laboratory Press, Cold Spring Harbor, NY.

Riddle, D.L., Swanson, M.M., and Albert, P.S. 1981. Interacting genes in nematode dauer larva formation. Nature 290: 668671.

Rogatsky, I., Luecke, H.F., Leitman, D.C., and Yamamoto, K.R. 2002. Alternate surfaces of transcriptional coregulator GRIP1 function in different glucocorticoid receptor activation and repression contexts. Proc. Natl. Acad. Sci. 99: 16701-16706.

Roy, P.J., Stuart, J.M., Lund, J., and Kim, S.K. 2002. Chromosomal clustering of muscle-expressed genes in Caenorhabditis elegans. Nature 418: 975-979.

Rubin, G.M., Yandell, M.D., Wortman, J.R., Gabor Miklos, G.L., Nelson, C.R., Hariharan, I.K., Fortini, M.E., Li, P.W., Apweiler, R., Fleischmann, W., et al. 2000. Comparative genomics of the eukaryotes. Science 287: 2204-2215.

Rundlett, S.E., Wu, X.P., and Miesfeld, R.L. 1990. Functional characterizations of the androgen receptor confirm that the molecular basis of androgen action is transcriptional regulation. Mol. Endocrinol. 4: 708-714.

Schena, M. and Yamamoto, K.R. 1988. Mammalian glucocorticoid receptor derivatives enhance transcription in yeast. Science 241: 965-967.

Sengupta, P., Colbert, H.A., and Bargmann, C.I. 1994. The C. elegans gene odr-7 encodes an olfactory-specific member of the nuclear receptor superfamily. Cell 79: 971-980.

Shtatland, T., Gill, S.C., Javornik, B.E., Johansson, H.E., Singer, B.S., Uhlenbeck, O.C., Zichi, D.A., and Gold, L. 2000. Interactions of Escherichia coli RNA with bacteriophage MS2 coat protein: Genomic SELEX. Nucleic Acids Res. 28: E93.

Sluder, A.E. and Maina, C.V. 2001. Nuclear receptors in nematodes: Themes and variations. Trends Genet. 17: 206-213.

Snow, M.I. and Larsen, P.L. 2000. Structure and expression of daf-12: A nuclear hormone receptor with three isoforms that are involved in development and aging in Caenorhabditis elegans. Biochim. Biophys. Acta 1494: 104-116.

Sompayrac, L. and Danna, K.J. 1990. Method to identify genomic targets of DNA binding proteins. Proc. Natl. Acad. Sci. 87: 3274-3278.

Sternberg, P.W. and Schmid, S.L. 1999. Caveolin, cholesterol and Ras signalling. Nat. Cell Biol. 1: E35-E37.

Thummel, C.S. 2001. Molecular mechanisms of developmental timing in C. elegans and Drosophila. Dev. Cell 1: 453-465.

Tsai, M.J. and O'Malley, B.W. 1994. Molecular mechanisms of action of steroid/thyroid receptor superfamily members. Annu. Rev. Biochem. 63: 451-486.

Tuerk, C. and Gold, L. 1990. Systematic evolution of ligands by exponential enrichment: RNA ligands to bacteriophage T4 DNA polymerase. Science 249: 505-510.

van Deurs, B., Roepstorff, K., Hommelgaard, A.M., and Sandvig, K. 2003. Caveolae: Anchored, multifunctional platforms in the lipid ocean. Trends Cell Biol. 13: 92-100.

Weinmann, A.S., Yan, P.S., Oberley, M.J., Huang, T.H., and Farnham, P.J. 2002. Isolating human transcription factor targets by coupling chromatin immunoprecipitation and $\mathrm{CpG}$ island microarray analysis. Genes \& Dev. 16: 235-244.

Wilson, T.E., Fahrner, T.J., Johnston, M., and Milbrandt, J. 1991. Identification of the DNA binding site for NGFI-B by genetic selection in yeast. Science 252: 1296-1300.

Yamamoto, K.R. 1995. Multilayered control of intracellular receptor function. Harvey Lect. 91: 1-19.

Yamamoto, K.R., Pearce, D., Thomas, J., and Miner, J.N. 1992. Combinatorial regulation at a mammalian composite response elements. In Transcriptional regulation (eds. S.L.
McKnight and K.R. Yamamoto), pp. 1169-1192. Cold Spring Harbor Laboratory Press, Cold Spring Harbor, NY.

Yamamoto, K.R., Darimont, B.D., Wagner, R.L., and IniguezLluhi, J.A. 1998. Building transcriptional regulatory complexes: Signals and surfaces. Cold Spring Harb. Symp. Quant. Biol. 63: 587-598.

Yoon, J.C., Puigserver, P., Chen, G., Donovan, J., Wu, Z., Rhee, J., Adelmant, G., Stafford, J., Kahn, C.R., Granner, D.K., et al. 2001. Control of hepatic gluconeogenesis through the transcriptional coactivator PGC-1. Nature 413: 131-138.

Zhang, H. and Emmons, S.W. 2000. A C. elegans mediator protein confers regulatory selectivity on lineage-specific expression of a transcription factor gene. Genes \& Dev. 14: 21612172 . 


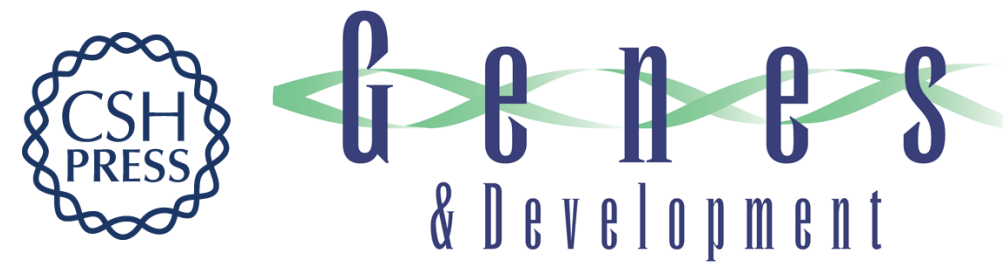

\section{Identification of $C$. elegans DAF-12-binding sites, response elements, and target genes}

Yuriy Shostak, Marc R. Van Gilst, Adam Antebi, et al.

Genes Dev. 2004, 18:

Access the most recent version at doi:10.1101/gad.1218504

Supplemental http://genesdev.cshlp.org/content/suppl/2004/09/29/18.20.2529.DC1
Material

References This article cites 63 articles, 28 of which can be accessed free at: http://genesdev.cshlp.org/content/18/20/2529.full.html\#ref-list-1

License

Email Alerting

Service

Receive free email alerts when new articles cite this article - sign up in the box at the top right corner of the article or click here.

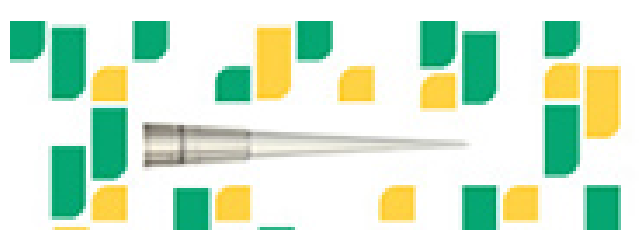

Focused on your science. 